\section{A) Check for updates}

Cite this: Mater. Adv., 2021, 2, 165

Received 5th November 2020, Accepted 23rd November 2020

DOI: 10.1039/d0ma00864h

rsc.li/materials-advances

\title{
From chemical curiosity to versatile building blocks: unmasking the hidden potential of main-group phthalocyanines in organic field-effect transistors
}

\begin{abstract}
Weiyi Zhou, ${ }^{a}$ Nathan J. Yutronkie, (D) a Benoît H. Lessard (D) ${ }^{\text {bc }}$ and Jaclyn L. Brusso (D) *a
Over the past few decades, metal phthalocyanines (MPcs) have been thoroughly investigated as active materials in organic field effect transistors (OTFTs) towards the commercialisation of flexible integrated circuits and displays. One of several advantages to MPCs as building blocks for OTFTs is the high degree of functionality, from which the choice of metal ion, substituents along the phthalocyanine framework and axially bound ligands can synergistically tune the physical and self-assembly properties of the material. Recent interest has been directed to the introduction of main-group elements as the central ion of MPcs as an avenue to install both hole and electron transport properties and improve device performance. In this review, we focus on the development of main-group phthalocyanines and their performances in OTFTs. General preparation of main-group MPcs are discussed for complexes integrated into OTFTs and further presented with a summary of their device performance.
\end{abstract}

\section{Introduction}

Since their discovery in the early 20 th century, ${ }^{1-3}$ metal phthalocyanines (MPcs) have played a pivotal role in paving research efforts across many scientific disciplines. The extensive

\footnotetext{
${ }^{a}$ Department of Chemistry and Biomolecular Sciences, University of Ottawa, 150 Louis Pasteur, Ottawa, ON K1N 6N5, Canada. E-mail: jbrusso@uottawa.ca

${ }^{b}$ Department of Chemical and Biological Engineering, University of Ottawa, 161 Louis Pasteur, Ottawa, ON K1N 6N5, Canada

${ }^{c}$ School of Electrical Engineering and Computer Science, University of Ottawa, 800 King Edward Ave. Ottawa, Ontario K1N 6N5, Canada
}

delocalization of $\pi$-electrons in the phthalocyanine framework affords the foundation for a molecular architecture in possession of impeccable stability and rich electronic behaviour. ${ }^{4-7}$ While MPcs were initially used as dyes and pigments due to their greenblue optical appearances, ${ }^{1}$ this class of molecules have since been exploited for widespread applications in catalysis, ${ }^{8}$ liquid crystals, ${ }^{9}$ fluorescent probes and photosensitisers, ${ }^{10}$ optoelectronic and redox-active materials, ${ }^{11-14}$ magnetic materials, ${ }^{15}$ sensors,${ }^{16}$ nonlinear optics, ${ }^{17}$ and molecular electronics, ${ }^{18-22}$ to name a select few.

Regarding molecular electronics, MPcs have gained tremendous traction towards the development of active materials

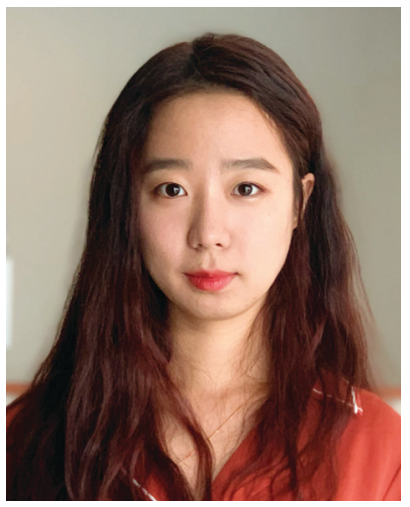

Weiyi Zhou
Weiyi Zhou received her Bachelor's degree (2018) in applied chemistry at Shenyang University of Chemical Technology, China. She is a Master student since September 2019 under the supervision of Prof. Jaclyn L. Brusso and Prof. Benoit H. Lessard in the University of Ottawa. Her research focuses on the design and synthesis of silicon phthalocyanines for electronic applications.

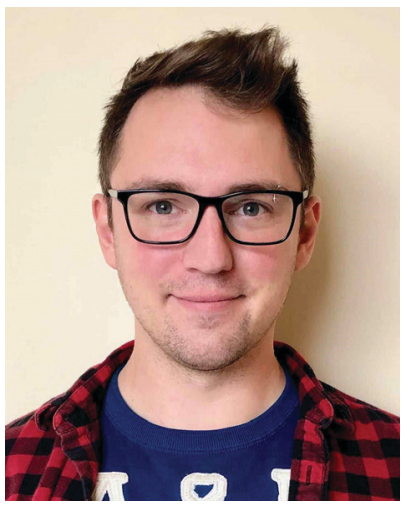

Nathan J. Yutronkie
Nathan J. Yutronkie received his $B S c$ degree in Biophamaceutical Science from the University of Ottawa in 2014, where he completed an honours project under the supervision of Prof. Jaclyn Brusso. He subsequently continued graduate studies under her direction and recently obtained his $P h D$ in Chemistry (2020). His research interests lie in the design and development of functional materials. 
in organic photovoltaics (OPVs), ${ }^{23-26}$ light-emitting diodes (OLEDs), ${ }^{27-30}$ and field-effect transistors (OFETs). ${ }^{31-34}$ Given the monumental role of FETs in modern-day devices, the implementation of MPcs as intrinsic organic semiconductors within these devices offers several advantages over their traditional inorganic counterparts. For one, synthetic procedures of MPcs are relatively facile, inexpensive, and ideal for massproduction at an industrial scale. These materials can also be processed with ease through conventional wet-based or vapour deposition methods on a range of compatible can be fabricated for flexible integrated circuits and displays. When juxtaposed to most organic molecules, the MPc building block itself is thermally and chemically robust in comparison, which reinforces the feasibility of their application in these molecular devices. Perhaps the greatest appeal of MPcs, especially for those aiming to enhance the performance of OTFTs, originates in the structural versatility of the molecule. Synthetic handles can be used to manipulate the properties of the material with control for the application at hand, thereby providing a means to rationally design MPc-based building blocks from a bottomup approach.

With that said, the molecular infrastructure of MPcs, comprised of four aza-bridged isoindoline subunits coordinated to a central metal inclusion, possesses four regions where the properties can be tailored accordingly by chemical modifications (Fig. 1). ${ }^{21}$ Functionalities can be enabled through the choice of the central ion $(\mathrm{M})$, the substituents along the peripheral and bay positions $\left(\mathrm{R}^{1}\right.$ and $\mathrm{R}^{2}$, respectively) of the phthalocyanine backbone $(\mathrm{Pc})$, and the ligands bound at the axial positions of the metal centre $(\mathrm{X}) \cdot{ }^{21}$ For sake of clarity and consistency, we herein refer to functionalised MPcs through the notation $\mathrm{X}^{1} \mathrm{X}^{2}-\mathrm{M}\left(\mathrm{R}_{m}^{1} \mathrm{R}_{n}^{2}\right) \mathrm{Pc}$, where 4-, 5- and 6-coordinate metal complexes are implied by the absence or inclusion of axial ligands $\mathrm{X}^{1}$ and $\mathrm{X}^{2}$, respectively. Furthermore, the degree and type of substitution along the Pc

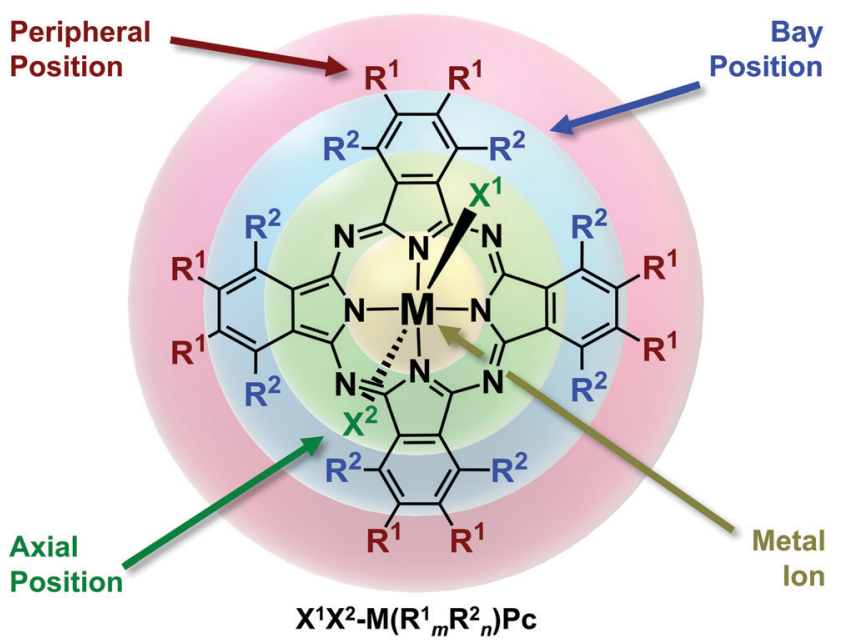

Fig. 1 Chemical structure of metal phthalocyanines highlighting the regions for chemical functionalisation. Adapted with permission from ref. 21. Copyright 2015 American Chemical Society.

framework is denoted by $\mathbf{R}_{m}^{1}$ and $\mathbf{R}_{n}^{2}$ in parentheses, where $m$ and $n=0-8$.

To further elaborate on the influences imposed by functionalisation, solubility is a key property that can be controlled through chemical moieties appending from the Pc framework and/or central ion. In general, MPcs are not inherently soluble in most common solvents as a consequence of aggregation via noncovalent interactions. Nonetheless, the attachment of flexible chains can aid in the disruption of these interactions or, in the case of polar and ionic groups, can enhance interactions with solvent molecules. On the other hand, judicious choice of these substituents can be used to rationalise favourable interactions (e.g., $\pi-\pi, \mathrm{C}-\mathrm{H} \cdots \mathrm{X}$, where $\mathrm{X}=$ heteroatoms, $\pi$, etc.) towards the preferential alignment and self-assembly of molecules in a

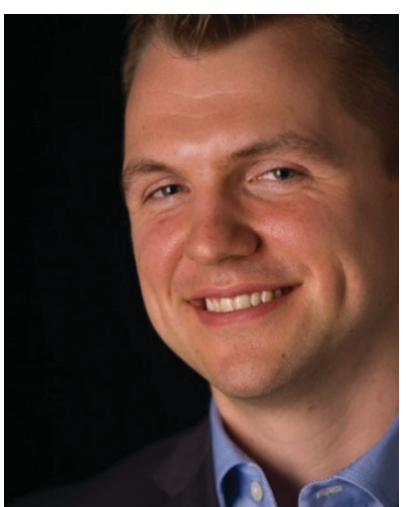

Benoît H. Lessard
Benoit Lessard obtained his PhD (2012) from McGill University in Polymer synthesis and reaction engineering. He then completed an NSERC Banting Postdoctoral Fellowship at the University of Toronto studying crystal engineering and engineering organic photovoltaics and organic light emitting diodes. In 2015, Benoît joined the Department of Chemical \& Biological Engineering at University of Ottawa as an Assistant Professor and Tier 2 Canada Research Chair, and was promoted to Associate Professor in May 2019. In 2020, he was cross appointed to the School of Electrical Engineering and Computer Science. Lessard's group focuses on the development of new materials and their integration into thin film electronic devices such as organic thin film transistors and sensors.

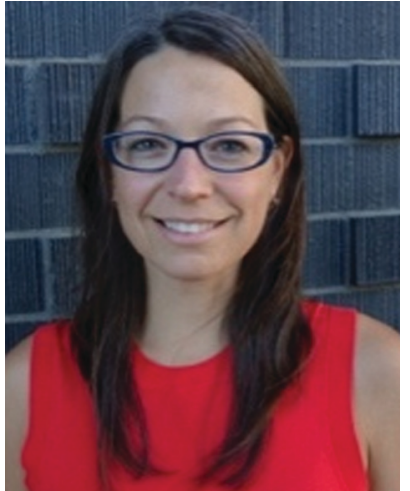

Jaclyn L. Brusso
Jaclyn Brusso obtained her PhD from the University of Waterloo under the direction of $R$. T. Oakley in 2006. Following an NSERC Postdoctoral Fellowship with D. Perepichka at McGill University and then with $S$. Holdcroft's group at Simon Fraser University, Jaclyn joined the University of Ottawa in 2010 as an Assistant Professor and was promoted to Associate Professor in 2016. Jaclyn's research program focuses on the design and development of novel organic/inorganic based optical, magnetic and electronic materials. 
condensed state. ${ }^{35-37}$ Moreover, these same interactions can ultimately be used to strengthen intermolecular interactions in order to enhance the charge-transport properties. ${ }^{38}$

Functionalisation can also alter the electronic structure of MPcs (e.g., influence the highest occupied and lowest unoccupied molecular orbitals; HOMO and LUMO, respectively), which are derived from the extensive $\pi$-system of phthalocyanine. Considering metalfree Pcs, large coefficients of both the HOMO and LUMO reside on the phenyl $\alpha$-carbon atoms (i.e., bay positions) and chelating nitrogen atoms, respectively. ${ }^{6,39,40}$ Hence, the orbital energies can be tailored by the direct implementation of electrondonating groups to destabilise MOs and electron-withdrawing groups which favour stabilisation. ${ }^{41,42}$ With the appropriate choice of substituents and central ion attached to the Pc framework, the energy levels can be synergistically perturbed with respect to the working electrode to afford unipolar n-type (charge carriers), p-type (hole carriers), or ambipolar (both) semiconductive materials, intrinsically. As for axial substituents, which are not directly attached to the Pc framework, electronic effects imparted by these groups are minimal in comparison. To date, MPcs studied in OTFTs have, in general, fallen into the category of p-type semiconductive materials, while reports of those leaning towards n-type are much scarcer. ${ }^{31}$ Presumably, this may reflect the large collection of easily accessible divalent transition metal complexes, which intrinsically favour p-type behaviour. Additionally, the lack of precursors available to construct electron-deficient Pc macrocycles capable of stabilising the LUMO energy levels for the injection of electrons may contribute to their slower progression.

Very recently, researchers have recognized an untapped potential in MPcs with the introduction of main-group elements as the central atom. ${ }^{38}$ By shifting away from transition metals, the higher oxidation states of the p-block elements, coupled with their electronegativity, have shown to afford stable unsubstituted MPcs that can behave intrinsically as n-type, and even ambipolar, in nature. Furthermore, the greater valencies for these ions provides an avenue to systematically assess the structure-property relationships through the presence of axial ligands, where most divalent MPcs are limited to substitutions along the Pc framework. Thus, the nature of organic semiconductors and the performance of devices can be optimised through these tuneable modes of functionalisation found within main-group Pcs. Although this class of MPcs show great promise, these materials on their own have several challenges in comparison to transition metal derivatives; the most obvious pertaining to the change in reactivity, which can impede synthetic preparations. Nonetheless, results are encouraging with the recent advances in synthetic methodologies for the preparation of main-group MPcs. By maximizing the utility of all synthetic handles to the fullest extent, it is merely a matter of time until these molecules showcase their true potential as versatile and high-performing building blocks in OTFTs.

To that end, the review herein aims to provide readers with a comprehensive overview of main-group phthalocyanines as prospective materials in OTFTs. Previous reviews on the subject of MPcs in OTFTs have primarily focused on the performances of transition metal complexes, ${ }^{43,44}$ while our focus is gravitated towards the preparative methods for this emerging class of MPcs and examine how functionalisation influences device performance. As the synthesis and reactivity for some MPcs have been covered in previous reviews, ${ }^{45-47}$ we will provide a brief outlook for these derivatives throughout the following section. Additionally, the synthesis of thallium and group 15 phthalocyanines have been excluded as the scope of this review pertains only to those complexes that have been implemented into OTFT devices.

\section{Synthesis of main-group phthalocyanines}

\subsection{General synthesis of metal phthalocyanines}

Highlighting the ubiquity of MPcs, over 95 metals and metalloids of the periodic table have been chelated to the indole nitrogen atoms of phthalocyanine. ${ }^{48}$ Of all these examples, two general preparative routes are typically employed as outlined in Scheme $1 .^{39,46,49}$ The most common synthetic approach involves the template method, which entails the cyclotetramerisation of phthalonitrile (1a) guided by a metal/metalloid precursor. While halide salts $\left(\mathrm{MX}_{n}\right.$ where $\left.\mathrm{X}=\mathrm{Cl}, \mathrm{Br}, \mathrm{I}\right)$ are most prevalently used as the template, the use of elemental metals or alloys, which are subsequently reduced in the process, have also been reported. These reactions are often carried out at elevated temperatures in non-aqueous high boiling solvents (e.g., nitrobenzene, quinoline, chlorinated benzenes and naphthalenes) and, depending on the nature of the reagents, several conditions can be altered to optimise MPc formation. For example, metal centres possessing strong Lewis acidity can activate the external nitrile groups, enabling nucleophilic addition of disassociated halide ions and anionic intermediates during the initiation and propagation
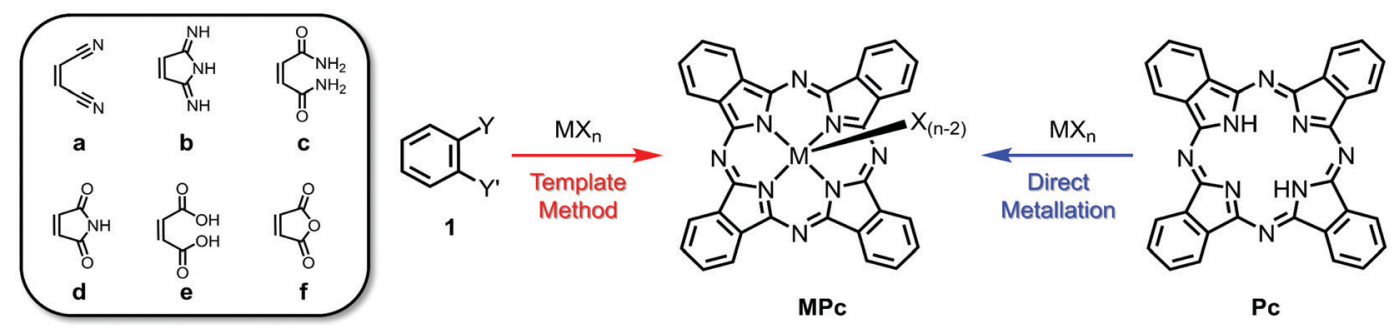

Scheme 1 General synthesis towards MPcs using phthalonitrile and related synthons (1a-f) via the template method (red) or direct metallation of metalfree Pcs (blue). 
steps of the macrocyclisation. Additives such as bases (e.g., 1,8-diazabicyclo(5.4.0)undec-7-ene, DBU) and initiators (e.g., alkoxides) have also been shown to be effective at promoting ring formation. In addition to phthalonitrile, other 1,2-disubstituted benzenes have been employed as synthons for the template method, including 1,3-diiminoisoindolines (DIII; 1b), phthalamides (1c), phthalimides (1d), phthalic acids (1e), and phthalic anhydrides (1f). Depending on the reagents chosen, additional sources of nitrogen may also be required for phthalocyanine formation such as urea in the presence of a catalyst $\left(\right.$ e.g., $\left.\left(\mathrm{NH}_{4}\right)_{2} \mathrm{MoO}_{4}\right)$. While the template method is by far the most employed preparative route for MPcs, direct metalation is also commonplace. The latter involves incorporation of the central ion following macrocycle formation, typically involving the reaction between a metal/metalloid halide salt and metal-free phthalocyanine.

In view of tailoring the properties of MPcs, functionalisation at the peripheral, bay and axial positions has been extensively explored. ${ }^{44}$ To that end, functionalisation can occur post MPc synthesis or via incorporation of functional groups to precursors prior to macrocycle formation. ${ }^{39,46,49}$ The latter is most common for targeting the bay and peripheral positions, whereas the former is most appealing for axial substitution. For modifications about the Pc framework, the generation of MPcs with symmetrically substituted phthalonitriles or related precursors (e.g., 1a-f) is preferred as predictable substitution patterns, specifically with $D_{4 \mathrm{~h}}$ symmetry, can be achieved rather than tediously modifying up to 16 positions post-cyclisation. ${ }^{49}$ Axial functionalisation on the other hand is best achieved through nucleophilic substitutions of an axial leaving group, such as chlorine and bromine atoms, bound to the central atom of preformed MPcs; however, the valency of the central ion must be considered as neutral divalent complexes are not generally capable of such functionalisation, whereas trivalent and tetravalent atoms offer one and two substituents, respectively.

As highlighted here, there are two main synthetic routes to generate MPcs, the template method and direct metalation. In moving towards main-group phthalocyanines, their preparation takes inspiration from this but some changes are necessary due to differences related to their reactivity, Lewis acidity, etc. This section will outline the synthesis and functionalisation of main-group Pcs for groups 13 and 14 elements and provide an overview of examples that sheds light towards their advancement as novel building blocks in OTFTs and related optoelectronic applications.

\subsection{Group 13 phthalocyanines}

2.2.1 Boron subphthalocyanines (metalloid Pcs). Contrary to the majority of metal precursors, boron-centred Lewis acids facilitate the macrocyclisation of phthalonitriles to yield an exceptional case of subphthalocyanines (X-BSubPc), which are composed of three isoindoline subunits oppose to four. ${ }^{50} \mathrm{Such}$ truncation of the phthalocyanine is to be expected given the smaller atomic size of boron, coupled to its trivalent oxidative state. ${ }^{51}$ Interestingly, the $14 \pi$-electron macroaromatic framework adopts a conical topography amending to the geometric constraints of the $\mathrm{sp}^{3}$-hybridised boron centre (Fig. 2). An axially bound substituent protrudes from the central boron

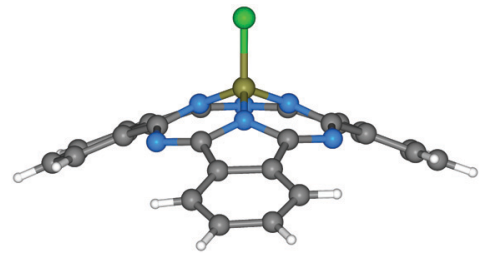

Fig. 2 Molecular structure of Cl-BSubPc. ${ }^{57}$ Reproduced using reported cif.

atom on the convex side of the macrocycle thereby affording $C_{3 \mathrm{v}}$ symmetry. This unique structural feature of X-BSubPcs derives their physicochemical properties, which has garnered considerable attraction towards their candidacy as active materials in organic optoelectronics applications. In particular, for OPVs, these building blocks act as electron acceptors and have shown great promise in replacing fullerene in these devices. ${ }^{26,52-56}$ To date, SubPcs have not been isolated without the presence of boron at the centre and attempts to exchange boron for other coordinating atoms has remained unsuccessful.

Since the synthesis, reactivity and reaction mechanism of a series of X-BSubPc derivatives have been well described in other review articles, ${ }^{58,59}$ herein we only briefly present some key aspects of their preparation. First synthesised serendipitously by Meller and Ossko in $1972,{ }^{60} \mathrm{Cl}-\mathrm{BSubPc}$ was prepared via the reaction of phthalonitrile with gaseous boron trichloride $\left(\mathrm{BCl}_{3}\right)$ in chloronaphthalene at $200{ }^{\circ} \mathrm{C}$, which afforded a cyclotrimerised product with an axially bound chlorine atom in $40 \%$ yield (Scheme 2). Since then, the reaction has been modified over the years to address issues with yield, purity and practicality, as it is the most common approach to generate X-BSubPcs. For example, Giribabu et al. utilised microwave irradiation for this cyclisation, increasing the yield of Cl-BSubPc up to $90 \%$ and reducing the reaction time to only 4-6 minutes. ${ }^{61}$ Torres and co-workers described a highly efficient method for the synthesis of Cl-BSubPcs, refluxing a $1 \mathrm{M}$ $\mathrm{BCl}_{3}$ solution in $p$-xylene with phthalonitrile, resulting in a yield of $82 \% .^{62}$ Through this approach, the boron reagent can be easily handled in solution oppose to gas, which allows for greater control over its stoichiometry and thus minimizing unwanted reactivity from excess Lewis acid. Additionally, the generation $\mathrm{Cl}_{2}$ as a side product is less pronounced through this method and significantly reduces the potential for halogenation along SubPc.

The cyclotrimerisation reaction has been adapted for the derivatisation of X-BSubPcs using pre-functionalised phthalonitriles. Meticulous attention must be given to the compatibility of the functional groups with the boron Lewis acid. Substituents such as

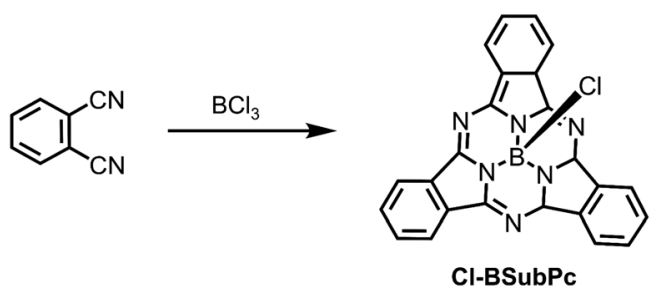

Scheme 2 Cyclotrimerisation of phthalonitrile with $\mathrm{BCl}_{3}$ affording $\mathrm{Cl}$ BSubPc. 
alkanes, halogens, nitrates, thioethers and sulfones are typically unaffected in the synthesis, whereas limitations are seen with alcohols, amines, ethers, carbonyls and related unsaturated functional groups among others, due to their proclivity to react with acidic substrates. As such, these functionalities are best introduced with protecting groups or post-cyclisation. ${ }^{59}$ Recently, modifications to the $\pi$-conjugated framework of phthalonitrile has provided an alternative avenue to optimise the optoelectronic properties of X-BSubPcs. For instance, the frontier MOs can be stabilized from the replacement of the benzo moiety for electron-deficient heterocycles, such as pyrazine, ${ }^{63}$ thiophene, ${ }^{64}$ and 1,2,5-chalcadiazoles. ${ }^{65-67}$ On the other hand, when aromatic hydrocarbons ${ }^{68-70}$ and heterocycles $^{71-75}$ are instead annulated to benzene, or even used to bridge other porphyrinoids, ${ }^{76-79}$ the extension of $\pi$-conjugation leads to bathochromic shifts in the main absorption band (Q-band).

Although less common, the boron reagent can be modified in these reactions in order to install non-halogen groups to the axial positions of X-BSubPc. For instance, treatment of phthalonitriles with $\mathrm{BPh}_{3}$ in the presence of base has led to both substituted and unsubstituted Ph-BSubPcs. ${ }^{80-82}$ An advantage to utilizing boron precursors with carbon-based groups is the tuning of the Lewis acidity $\left(\right.$ e.g., $\left.\mathrm{BPh}_{n} \mathrm{Cl}_{(3-n)} ; n=1-3\right)$, which subsequently suppresses undesirable reactivity with sensitive functionalities. ${ }^{66,83}$ As a trade-off, the stronger $\mathrm{B}-\mathrm{C}$ bonds noticeably hinders product yields, due to the difficulties with eliminating the excess groups attached to the boron atom. In one instance, DIIIs were used as an alternative to phthalonitrile for these reactions. Regarding $\mathrm{Ph}-\mathrm{B}(t-\mathrm{Bu})_{3} \mathrm{SubPc}$, reaction of $\mathrm{BPh}_{3}$ with the either the corresponding DIII or phthalonitrile led to small differences in their yields (i.e., $3 \%$ and $5 \%$, respectively). While the use of this precursor did not prove to be advantageous in the synthesis, DIII has found tremendous success in the preparation of silicon phthalocyanines, which will be discussed in detail in the following section.

Due to the lability of the B-Cl bond, various axially substituted BSubPcs can be easily prepared by displacing the halide with different nucleophiles. Such functionalisation thereby introduces an additional molecular fragment, which can be used to enhance structure-property relationships. For example, the substitution of the axial halide by a hydroxide group can be achieved by refluxing a suspension of $\mathrm{X}$-BSubPc $(\mathrm{X}=\mathrm{Cl}$ or $\mathrm{Br})$ in water, ${ }^{84}$ or toluene/ $\mathrm{SiO}_{2}{ }^{85}$ Torres' group devised an optimised method to synthesise phenol derivatives from Cl-BSubPcs by heating the appropriate phenols in toluene. ${ }^{62,86}$ In their following research, fullerene $\left(\mathrm{C}_{60}\right)$ was introduced in the axial position of BSubPcs by 1,3 dipolar cycloaddition reaction between formyl-substituted BSubPcs and $\mathrm{C}_{60}$ in the presence of $\mathrm{N}$-methylglycine. ${ }^{86}$ Besides water and phenol, ${ }^{85}$ other nucleophiles such as carboxylic acids, ${ }^{87}$ alkyl alcohols, ${ }^{68,88,89}$ and even some cholesterols ${ }^{89}$ can also yield corresponding axial-substituted derivatives. A ferrocene-based derivative, $\mathrm{FcCO}_{2}$-BSubPc, was obtained by refluxing a mixture of ferrocene carboxylic acid and $\mathrm{Cl}-\mathrm{BSubPc}$ in $o$-dichlorobenzene (o-DCB), resulting in new donor-acceptor dyads that are potentially useful in light-harvesting elements. ${ }^{87}$ In order to synthesise trialkylsiloxy derivatives $\left(\mathrm{R}_{3} \mathrm{SiO}\right)-\mathrm{BSubPcs}(\mathrm{R}=$ alkyl), Zyskowski and Kennedy first heated a mixture of sodium metal and trihexylsilanol in anhydrous chlorobenzene to form the sodium salt, then added Cl-BSubPc and subsequently refluxed the reaction mixture for 1.5 hours. ${ }^{68}$ Alternatively, $\left(\mathrm{R}_{3} \mathrm{SiO}\right)$-BSubPcs can also be obtained through a two-step reaction, first preparing the HO-BSubPc, then functionalizing it with trihexylchlorosilane via nucleophilic substitution, as reported by Martínez-Díaz et al. ${ }^{84}$ In 2011, Bender and co-workers discovered that phthalimides can also function as suitable nucleophiles in the displacement of the chloride in Cl-BSubPc to form phthalimido-boron subphthalocyanines. ${ }^{90}$ Interestingly, $\sim 10 \%$ of $\mu$-oxo-(BSubPc) $)_{2}$ was also obtained as a by-product suggesting hydrolysation of Cl-BSubPc to HO-BSubPc occurs in the presence of trace amounts of water, which subsequently reacts with another equivalent of Cl-BSubPc or condenses with another HO-BSubPc. ${ }^{90}$

2.2.2 Aluminium, gallium and indium phthalocyanines (metal Pcs). The remaining elements of group 13 can all be introduced into the Pc framework. Within this section, we direct our attention on their syntheses, specifically for aluminium, gallium and indium, from which this family of molecules has been previously studied in OTFTs. Out of the three, aluminium was among a series of elements in the initial studies of metal phthalocyanines pioneered by Linstead in $1934 .{ }^{91}$ In his report, the reaction between phthalonitrile and aluminium trichloride $\left(\mathrm{AlCl}_{3}\right)$ in heated quinoline led to the formation of Cl-AlPc. He also noted Cl-AlPc can be generated through the direct insertion of $\mathrm{AlCl}_{3}$ to metal-free Pc with the subsequent release of $\mathrm{HCl}$. Years later, Colaitis applied the template method to phthalonitrile using trivalent metal halides of gallium and indium to afford $\mathrm{Cl}-\mathrm{GaPc}$ and Cl-InPc, respectively. ${ }^{92}$ Single crystals have been grown of axial-halide substituted complexes, from which each trivalent metal ion puckers out-of-plane to the phthalocyanine framework, presumably as a consequence of their larger ionic radii (Fig. 3). ${ }^{93,94}$

Additionally, DBU has been has shown to be effective at catalyzing the cyclotetramerisation of phthalonitrile in solution. ${ }^{96-102}$ As a result, a range of peripherally-functionalised Cl-MPc derivatives have been obtained that bear, for example, alkyl, ${ }^{99,101}$ thioethers, ${ }^{96}$ phenoxy, ${ }^{98,103}$ and pyridyloxy. ${ }^{104}$ Extended $\pi$-conjugated naphthalocyanines of each trivalent metal ion (MNcs) have also been reported using similar preparative methods as their X-MPc counterparts. More specifically, the synthesis of X-InNcs usually starts from the appropriate naphthalonitriles or DIIIs, which can be prepared from $o$-xylenes as reported previously. ${ }^{101,102,105}$ It has been demonstrated that the use of DIII affords a preformed naphthalocyanine core, which are much more reactive than the corresponding dicyanonaphthalenes. ${ }^{105}$ Apart from that, HO-AlPc ${ }^{106,107}$ and HO-GaPc ${ }^{100}$ derivatives can be directly synthesised based on dicarboxylic acid or dianhydride, with the presence of urea and catalyzed by ammonium molybdate.

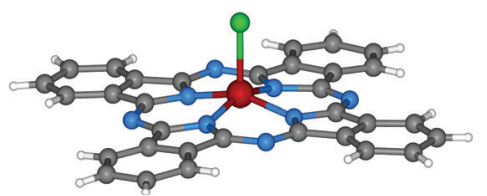

Fig. 3 Molecular structure of Cl-AIPc. ${ }^{95}$ Reproduced using reported cif. 
Axial replacement of $\mathrm{Cl}-\mathrm{MPc}(\mathrm{M}=\mathrm{Al}, \mathrm{Ga}, \mathrm{In})$ can be facilitated by nucleophilic addition. Hydroxy derivatives are commonly obtained by hydrolyzing the corresponding Cl-MPc under acidic or basic conditions. For instance, HO-AlPc can be synthesised from the reaction of Cl-AlPc in the presence of $\mathrm{NH}_{4} \mathrm{OH}$ in a refluxing pyridine solution. ${ }^{108} \mathrm{HO}-\mathrm{GaPc}$ can be prepared by casting a concentrated sulfuric acid solution of Cl-GaPc into water followed by neutralisation with $\mathrm{NH}_{4} \mathrm{OH} .{ }^{109}$ Based on the hydroxy derivatives, more axial substituted complexes can be prepared. For example, the conversion of HO-AlPc to F-AlPc can be achieved by treating the former with hydrofluoric acid $(\sim 48 \mathrm{wt} \%)^{108,110,111}$ Similar conversion was achieved in the case of Cl-GaPc. ${ }^{110}$ In addition, Grant et al. reported a more straightforward and safer one-step synthetic route to obtain F-MPc from Cl-MPc (M = Al, Ga) directly, using cesium fluoride as the fluoride source in high boiling polar solvents. ${ }^{112}$ Phenol complexes are also commonly used nucleophiles that can introduce phenoxy groups onto the centre of MPcs, such as $p$-methoxyphenol, ${ }^{113}$ pentafluoro phenol, ${ }^{114}$ $p$-nitrophenol, ${ }^{114} p$-chlorophenol, ${ }^{99}$ etc. The introduction of aryl groups to the axial position of Pcs can be achieved by using appropriate Grignard reagents, ${ }^{99,101,103}$ or lithium salts for the introduction of aryl substituents ${ }^{101}$ upon nucleophilic substitutions of Cl-MPcs. Chen et al. ${ }^{115}$ even introduced InPcs into a polymer backbone by reacting Cl-InPc with polystyrene $(\mathrm{MgBr})_{n}$. Apart from that, Sakai et al. ${ }^{116}$ synthesised poly(hydroxyimide)AlPcs copolymer by the reaction of poly(hydroxyimide) with aluminium phthalocyanine triflate, which was obtained from Cl-AlPc and silver triflate. MPcs were also demonstrated to play an important role in the field of graphite materials, in which the first soluble graphite oxide (GO) axially substituted GaPc hybrid material was prepared by Li et al. ${ }^{117}$ in 2011. This was achieved via the reaction of Cl-GaPc with GO in DMSO at $110{ }^{\circ} \mathrm{C}$ in the presence of $\mathrm{K}_{2} \mathrm{CO}_{3}$.

\subsection{Group 14 phthalocyanines}

2.3.1 Silicon and germanium phthalocyanines (metalloid Pcs). Incorporation of group 14 atoms into MPcs offers the potential for stable hexacoordinate complexes given the accessibility to tetravalent oxidation states. Advantageously, this provides an additional synthetic handle to fine-tune the properties of the material, specifically solubility and the solid-state arrangement, as two axial substituents are present (Fig. 4).

The first attempts to generate silicon phthalocyanines were focused on the direct metalation of Pc by Linstead. ${ }^{119}$ Although unsuccessful, these involved pressure tube reactions comprised of disodium phthalocyanine and silicon tetrachloride $\left(\mathrm{SiCl}_{4}\right){ }^{119}$ Several decades later, Joyner and co-workers described the

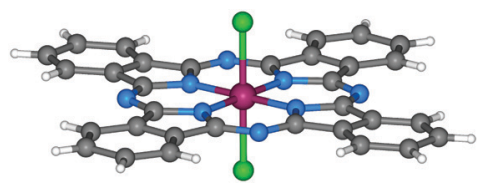

Fig. 4 Molecular structure of $\mathrm{Cl}_{2}-\mathrm{SiPc}^{118}$ Reproduced using reported cif. formation of what they proposed to be dichlorosilicon phthalocyanine $\left(\mathrm{Cl}_{2}\right.$-SiPc) via the template method in $1960,{ }^{120}$ which was later supported by elemental analysis. ${ }^{121}$ While reacting phthalonitrile with silicon $\mathrm{SiCl}_{4}$ in refluxing quinoline affords $\mathrm{Cl}_{2}$-SiPc, only $7 \%$ of the desired product was isolated using this approach. In the same report, various silicon sources were explored including trichloromethylsilane, trichloromethylsilane, and hexachlorodisiloxane to varying levels of success. Product formation was not observed for the former two reagents; however, the synthetic route employing hexachlorodisiloxane provided a yield of approximately $43 \%$. Alternatives to phthalonitrile were reviewed in a study by Kenney in 1964, which demonstrated that both $o$-cyanobenzamide and DIII could be converted to $\mathrm{Cl}_{2}$-SiPc in $35 \%$ and $71 \%$ yields, respectively. ${ }^{122}$ The yield of this reaction has been enhanced by Marks and co-workers through their modified procedure that introduces DIII once the reaction temperature reached $200{ }^{\circ} \mathrm{C}$, which afforded yields reaching $80 \% .{ }^{123}$ Additionally, Noboru et al. synthesised $\mathrm{Cl}_{2}$-SiPc in a $90 \%$ yield by replacing quinoline with tetrahydronapthalene and tri- $n$-butylamine, ${ }^{124}$ yet the authors note that the crude product contains as much as $30-50 \%$ impurities.

The vast majority of derivatisation with respect to silicon phthalocyanines is directed to axial functionalisation (vide infra), while peripherally substituted complexes are few and far between. This may be attributed to the lack of commercially available DIIIs, along with their less than ideal preparative routes, which require the use of sodium metal and a constant flow of ammonia gas in a refluxing methanolic solution of phthalonitrile for several hours. ${ }^{122}$ However, an alternative approach to the classical preparative route for DIII was recently reported by Brusso and co-workers (Scheme 3) that employs $\mathrm{LiN}(\mathrm{TMS})_{2} \cdot \mathrm{Et}_{2} \mathrm{O}$ as a nucleophilic source of nitrogen. ${ }^{125}$ This new route eliminates the undesired expenses attributed to the strenuous reaction conditions required and the hazardous reagents employed in the preparation of DIII, thus it is anticipated that other derivatives with modified molecular frameworks can now be explored.

In contrast to $\mathrm{X}_{2}$-SiPcs, tetravalent germanium complexes are readily prepared by the template reaction of phthalonitrile and germanium tetrachloride $\left(\mathrm{GeCl}_{4}\right)$ to afford dichlorogermanium

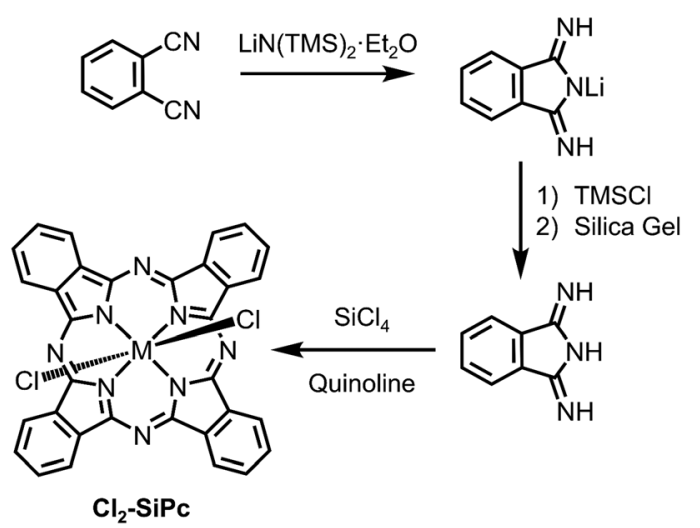

Scheme 3 Synthetic routes in the preparation of $\mathrm{Cl}_{2}-\mathrm{SiPc}$, including the preparation of DIII. ${ }^{125}$ 
phthalocyanine $\left(\mathrm{Cl}_{2}\right.$-GePc). ${ }^{123,126}$ Alternatively, $\mathrm{Cl}_{2}$-GePc can also be prepared by mixing powdered germanium metal with phthalonitrile under a stream of $\mathrm{ICl}$ vapor at $\sim 160{ }^{\circ} \mathrm{C}$. The latter route affords isomorphous triclinic crystals of $\mathrm{Cl}_{2}-\mathrm{GePc}$, whereas monoclinic crystals of $\mathrm{Cl}_{2}-\mathrm{GePc}$ can be prepared via the same reaction at $\sim 180{ }^{\circ} \mathrm{C}^{127}$ At these temperatures, melted phthalonitrile undergoes catalytic tetramerisation while two-electron transfer occurs from the Ge atom to the Pc ring simultaneously and two other electrons are transferred from the Ge atom to $\mathrm{ICl}$ forming $\mathrm{I}^{-}$and $\mathrm{Cl}^{-}$ions. ${ }^{127}$ In 2017, Slodek et al. reported a less common synthetic route for $\mathrm{Cl}_{2}-\mathrm{GePc}$ in which the product was obtained by reacting 4-nitrophthalic anhydride with $\mathrm{GeCl}_{4}$ using urea as a source of ammonia and ammonium molybdate as the catalyst. ${ }^{128}$

In 1970, Joyner and co-workers ${ }^{129}$ reduced $\mathrm{Cl}_{2}$-GePc with sodium borohydride $\left(\mathrm{NaBH}_{4}\right)$ or tin dichloride $\left(\mathrm{SnCl}_{2}\right)$ to obtain divalent germanium phthalocyanine (GePc), which is a very lightsensitive compound. The authors also noted that a large excess of $\mathrm{NaBH}_{4}$ led to complete decomposition of the ring system. Interestingly, GePc is surprisingly resistant to oxidation back to form $\mathrm{X}_{2}$-GePc, while a similar oxidation process is much easier for divalent SnPc (vide infra). ${ }^{119}$ In the case of GePc, phthalocyanine oxidation and decomposition usually occur before the oxidation of $\mathrm{Ge}^{\mathrm{II}}$ to $\mathrm{Ge}^{\mathrm{IV}}$, potentially due to the smaller covalent radius of $\mathrm{Ge}^{\mathrm{II}}$ (compared to $\mathrm{Sn}^{\mathrm{II}}$ ), which could allow it to fit tightly within the Pc plane thereby enhancing its stability. ${ }^{45}$

The synthesis of dihydroxysilicon phthtalocyanine ((HO) $)_{2}$-SiPc) and dihydroxygermanium phthalocyanine $\left((\mathrm{HO})_{2}-\mathrm{GePc}\right)^{123,126}$ have been extensively reported with the most common preparative method achieved via hydrolysis of their dichloride counterparts. In these processes, both strongly acidic (typically involving concentrated sulfuric acid) ${ }^{121}$ and basic (employing, for example, sodium hydroxide, ${ }^{123,130}$ cesium hydroxide ${ }^{131}$ concentrated aqueous ammonia, ${ }^{121}$ sodium methoxide, ${ }^{122}$ etc.) conditions can be used to hydrolyze the $\mathrm{Cl}_{2}-\mathrm{MPc}$ complexes. In the case of $(\mathrm{HO})_{2}$ SiPc, it can also be prepared directly from DIII. As well, the two axial positions of the tetravalent metal centres can be displaced by various substituents such as phenyl, ${ }^{132}$ phenoxy, ${ }^{25,126,128,131}$ siloxy, ${ }^{121,126,131,133}$ alkynyl, ${ }^{134}$ diethylaminophenoxyethoxy, ${ }^{135}$ 1benzylpiperidin-4-oxy, ${ }^{136}$ and even graphene ${ }^{137}$ or benzyl ester dendrimers. ${ }^{138}$ For this reason, a number of symmetrically and asymmetrically substituted $\mathrm{X}_{2}$-SiPc and $\mathrm{X}_{2}$-GePc derivatives have been developed over the years. The majority of axially substituted systems can be prepared via nucleophilic substitution of $\mathrm{Cl}_{2}$ $\mathrm{MPc}^{25,128,132,136,138}$ or $(\mathrm{HO})_{2}-\mathrm{MPc},{ }^{120,121,126,131}$ while there are also examples starting from DIII for silicon-based derivatives. For example, Barker et al. ${ }^{132}$ first synthesised chloro phenyl silicon phthalocyanine chloride $((\mathrm{Cl})(\mathrm{Ph})-\mathrm{SiPc})$ by the reaction between DIII and phenyltrichlorosilane. They then synthesised a series of axial-substituted esters and bis-ether through nucleophilic displacement of one or two $\mathrm{Cl}$ substituents from either $(\mathrm{Cl})(\mathrm{Ph})-\mathrm{SiPcCl}$ or $\mathrm{Cl}_{2}$-SiPc, respectively. ${ }^{132}$ The introduction of various substituents can not only enhance the solubility of MPcs, but also suppress aggregation by introducing steric hindrance. ${ }^{139,140}$

2.3.2 Tin and lead phthalocyanines (metals Pcs). It is well known that tin is stable in both the +2 and +4 oxidation states, ${ }^{141}$ thus in Pc based complexes it can exist in either divalent or tetravalent form. Lead on the other hand only exhibits bivalency, which limits functionalisation of PbPcs to the phthalocyanine framework. Template cyclisation of phthalonitrile using $\mathrm{MCl}_{n}$ (where $\mathrm{M}=\mathrm{Sn}$ and $\mathrm{Pb} ; n=2$ or 4 ) in a refluxing high boiling point solvent is an effective preparative method, giving rise to dichlorotin phthalocyanine $\left(\mathrm{Cl}_{2} \text {-SnPc }\right)^{123,142}$ and lead phthalocyanine (PbPc). ${ }^{143} \mathrm{Cl}_{2}$-SnPc was first synthesised by the Linstead and co-workers in which the reaction between phthalonitrile and $\mathrm{SnCl}_{2}$ was violently exothermic, affording $\mathrm{Cl}_{2}$-SnPc in a $90 \%$ yield. ${ }^{119}$ Subsequent work by Kroenke and Kenney investigated the same reaction in 1-chloronaphthalene, ${ }^{142}$ which Dirk et al. ${ }^{123}$ then modified to obtain $\mathrm{Cl}_{2}$-SnPc in an excellent yield of $96 \%$. The synthesis of isomorphous triclinic and monoclinic crystals of $\mathrm{Cl}_{2}$-SnPc was accomplished in the identical fashion to that of $\mathrm{Cl}_{2}$-GePc (vide supra), except metallic $\mathrm{Sn}$ was used instead of Ge. ${ }^{127}$ Another synthetic procedure involving metal-free phthalocyanine $\left(\mathrm{H}_{2} \mathrm{Pc}\right)$ as carried out using commercially available dilithium phthalocyanine, ${ }^{144}$ where $\mathrm{Sn}$ was introduced into the Pc ring by boiling a mixture of $\mathrm{H}_{2} \mathrm{Pc}$ and $\mathrm{SnCl}_{2}$ in dry quinoline. This reaction requires high energy, due to the relatively large size of Sn atoms for coordination with Pc ligand. Here, the high boiling point solvent was used for the coordination of both ions and the reactions were performed by preheating of the starting compound to allow the high yielded coordination reactions. ${ }^{144}$ Additionally, the preparation of MNcs can be achieved by reaction between 2,3-naphthalenedicarbonitrile with $\mathrm{SnCl}_{2}$ or $\mathrm{SnCl}_{4}$ gives rise to $\mathrm{SnNc}^{145}$ and $\mathrm{Cl}_{2}$-SnNc, ${ }^{145}$ respectively.

Divalent tin phthalocyanine (SnPc) can be obtained by mixing metallic tin and phthalonitrile and heating to $300{ }^{\circ} \mathrm{C}$ without solvent. ${ }^{119}$ In addition, SnPc can also be prepared by the reduction of its tetravalent counterpart (e.g., $\mathrm{Cl}_{2}$-SnPc). For instance, Kroenke and Kenney ${ }^{142}$ reduced $\mathrm{Cl}_{2}$-SnPc with anhydrous $\mathrm{SnCl}_{2}$ in refluxing quinoline. ${ }^{142}$ Linstead and co-workers ${ }^{119}$ passed hydrogen through a solution of $\mathrm{Cl}_{2}$-SnPc in boiling quinoline to obtain SnPc. They also showed oxidation of solid SnPc with dry chlorine gas afforded the tetravalent dichlorotin chlorophthalocyanines, where chlorination was observed along the phthalocyanine framework. All the records suggest that interchange between stannous and stannic phthalocyanines can be readily affected (Scheme 4).

It is noteworthy that lead phthalocyanine $(\mathrm{PbPc})$ is kind of abnormal compared with other phthalocyanines in which the

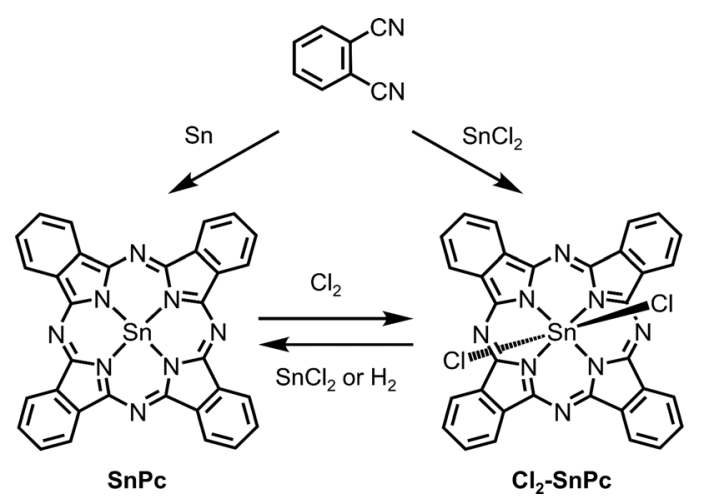

Scheme 4 Synthetic routes to divalent $\mathrm{SnPc}$ and tetravalent $\mathrm{Cl}_{2}-\mathrm{SnPc}$. 


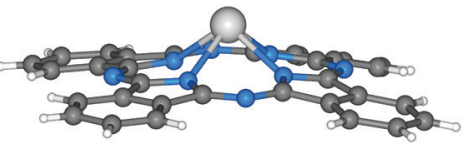

Fig. 5 Molecular structure of PbPc. ${ }^{148}$ Reproduced using reported cif.

central elements belong to group 14. Since the central $\mathrm{Pb}$ ion only exhibits bivalency, axial substituents cannot be attached to the central atom, thereby limiting functionalisation (Fig. 5). In general, PbPcs can be prepared by the violently exothermic reaction between litharge $(\mathrm{PbO})$ and phthalonitrile, ${ }^{119,146}$ or by the more common reaction between phthalonitrile and $\mathrm{PbCl}_{2}{ }^{143}$ Moreover, extended PbNcs have been achieved through similar reactions by treating 2,3-naphthalenedicarbonitrile with $\mathrm{PbCl}_{2} \cdot{ }^{147}$

So far, the literature of axially substituted $\mathrm{X}_{2}$-SnPcs is notwell established, especially compared to $\mathrm{X}_{2}$-SiPcs. Similar to $(\mathrm{HO})_{2}$-SiPc and $(\mathrm{HO})_{2}-\mathrm{GePc},(\mathrm{HO})_{2}-\mathrm{SnPc}^{123,142}$ can also be prepared via the hydrolysis of $\mathrm{Cl}_{2}$-SnPc in the presence of strong acid or base. Axial substituted reactions for SnPcs ${ }^{149}$ have been achieved via nucleophilic substitution of either $(\mathrm{HO})_{2}$-SnPc or $\mathrm{X}_{2}$-SnPc. For example, Rafaeloff et al. ${ }^{150}$ prepared $\left(\mathrm{Ph}_{3} \mathrm{CO}\right)_{2}$-SnPc and $\left(\mathrm{Ph}_{3} \mathrm{SiO}\right)_{2}$-SnPc by reacting $\mathrm{I}_{2}$-SnPc or $(\mathrm{HO})_{2}$-SnPc with triphenylcarbinol or triphenyisilanol, respectively. Then in 2002 Maree et al. synthesised diestronetin phthalocyanine by modifying their method used for substitution with silanols. ${ }^{149}$ In 2019, Lessard and co-workers reported the synthesis of two soluble axially functionalised tin phthalocyanines with silyl ethers, $\left((n-\mathrm{Bu})_{3} \mathrm{SiO}\right)_{2}$-SiPc and $\left((n-\mathrm{Hx})_{3} \mathrm{SiO}\right)_{2}-\mathrm{SiPc}(\mathrm{Bu}=$ butyl; $\mathrm{Hx}=$ hexyl $)$, by the reaction between $\mathrm{Cl}_{2}$-SnPc and corresponding tri- $n$-alkylchlorosilanes in the presence of $\mathrm{NaOH}$ and Aliquat HTA-1, a phase transfer catalyst, in boiling chlorobenzene. ${ }^{151}$ In early 2020, Lessard's group extended their research to the synthesis and the OTFT application of complexes with electron-deficient polyfluorinated aryl substituents at the axial positions, including $\left(\mathrm{F}_{5} \mathrm{Ph}\right)_{2}-\mathrm{SnPc}$ and $(2,4,6-$ $\left.\mathrm{F}_{3} \mathrm{Ph}\right)_{2}$-SnPc. ${ }^{34}$ The reaction of $\mathrm{Cl}_{2}$-SnPc with fluorophenol in refluxing chlorobenzene resulted in bis(fluorophenoxy) substituted SnPcs in good yields of $\sim 80 \%$.

\subsection{Group 15 and 16 phthalocyanines}

Synthesis of group 15 MPcs dates back to Linstead's investigations in $1938,{ }^{91}$ and since then, trivalent or pentavalent complexes of arsenic, antimony and bismuth have been synthesised. ${ }^{45}$ Despite this, the fabrication of OTFTs utilizing these systems as organic semiconductors has not been explored, and as the scope of this review encompasses the development of OTFTs with main-group phthalocyanines, we direct the reader to a previous review. ${ }^{45}$ However, it should be mentioned that, in addition to the metals and metalloids within this group, phosphorus represents the only non-metallic element found to coordinate to the central pocket of the phthalocyanine. Furuyama and Kobayashi have significantly contributed to the rational design of functionalised phthalocyanines with pentavalent phosphorus centres possessing absorption bands in the infrared region. For more information on synthesizing these complexes and modulating the optical energy gap via chemical modifications, we direct the reader to their recent review. ${ }^{47}$ As for group 16 phthalocyanines, no complexes have been reported in the literature to the best of our knowledge. Thus, there remains an untapped potential to explore the synthesis of MPcs bearing these elements and their integration into OTFTs.

\section{Applications of phthalocyanines in organic field-effect transistors}

\subsection{Organic field effect transistors (OFETs)}

From their outstanding properties to their chemical stability, MPcs have been sought out as tuneable active materials in OPVs, ${ }^{23-26}$ OLEDs, ${ }^{27-30}$ and, of particular importance to this review article, in OFETs. The charge transport properties of MPcs make them ideal organic semiconductors and, for the purposes of this review article, we will focus on their use in OFETs. While a great deal of research is focused on various aspects of device optimisation, ${ }^{152-158}$ attention will be placed on the employment of main-group Pcs in the active layer and their configurations into devices. Before getting into the specifics, we will provide a brief introduction on the basics of OFET devices.

3.1.1 Device structure, operation and materials. FETs are three-electrode devices that generally consist of five components: the substrate, which acts as a solid support for the device; the gate electrode, which modulates the conductivity of the active layer; the source and drain (S/D) electrodes where charge enters and leaves the active layer, respectively; ${ }^{159}$ the insulating layer that prevents current flow between the gate and the S/D electrodes; and finally the active layer, which facilitates charge transport from the source to the drain electrodes. In the case of OFETs, the active material consists of an organic semiconductor that can be switched between on (i.e., conductive) and off (i.e., non-conductive) states remotely through an electric gate by the gate electrode. Due to the inherent properties of organic semiconductors, the active layer in OFETs can be deposited by various techniques, including vapor deposition ${ }^{38,160-162}$ or solution processing ${ }^{11,12,26}$ methods. While the S/D electrodes are directly connected to the semiconductor and the gate electrode is separated by an insulating layer in all OFETs, various device configurations are commonly employed based on the relative position of the electrodes. The four most common include top contact/bottom gate (TC/BG, Fig. 6a), bottom contact/ bottom gate (BC/BG, Fig. $6 \mathrm{~b})$, bottom contact, top gate $(\mathrm{BC} / \mathrm{TG}$, Fig. 6c), and top contact, top gate (TC/TG, Fig. 6d) structures.

The basic principle behind OFETs involves modulation of the current between the S/D electrodes by application of a voltage to the gate electrode. A bias $\left(V_{\mathrm{DS}}\right)$ is applied between the S/D electrodes, and depending on the gate voltage $\left(V_{\mathrm{G}}\right)$, current flows through the semiconductor layer. When no $V_{\mathrm{G}}$ or a small $V_{\mathrm{G}}$ is applied, only negligible current flows across the semiconductor due to a lack of mobile charge carriers. This state is called the device "off" state. If the applied $V_{\mathrm{G}}$ is larger than the threshold voltage $\left(V_{\mathrm{T}}\right)$ of the device, charge carriers can be electrostatically induced and the current flow $\left(I_{\mathrm{D}}\right)$ between the S/D electrodes increases, thus the device is "turned on". During this process, specific charge carriers will transfer between the S/D electrodes, which is oriented parallel to the 

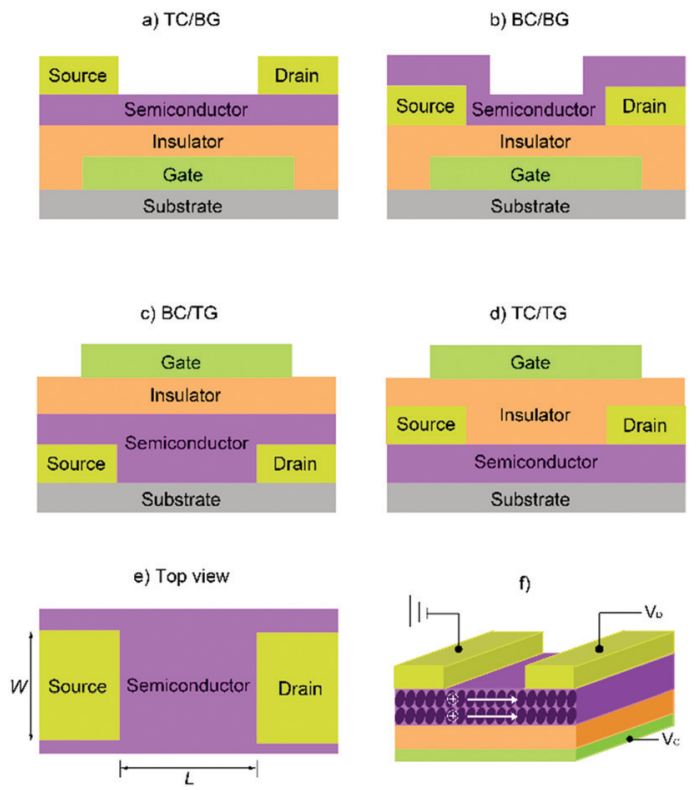

Fig. 6 Four typical OFET configurations: (a) top contact, bottom gate (TC/BG); (b) bottom contact, bottom gate (BC/BG); (c) bottom contact, top gate (BC/TG); (d) top contact, top gate (TC/TG). (e) The top view of sourceand-drain electrodes and semiconductor layer. (f) A thin-film transistor with a flat film as the charge-transporting layer. The image ( $f$ ) is reprinted with permission from ref. 163. Copyright 2011, Wiley-VCH.

substrate surface. In order to achieve this, molecules in the semiconductor layer are required to "stand" on the substrate to ensure the $\pi-\pi$ stacking direction is parallel to the substrate. ${ }^{164}$ An OFET-device based on the film with vertical channels with respect to the substrate for charge transport is shown in Fig. 6 f. When a negative gate voltage is applied, positive charges (i.e., holes) act as charge carriers; such transistors are defined as p-channel (or p-type) OFETs and the corresponding semiconductor in the active layer is a p-type semiconductor. Conversely, an n-channel (or n-type) OFET occurs when a positive gate voltage is applied and negative charge carriers (i.e., electrons) flow through the active material. In this case the organic semiconductor is defined as n-type. In some cases, ambipolar charge transport in single component OFETs can be realised by reducing the injection barrier of holes and electrons.

Related to MPc-based OFETs, some common features are noted. For example, the substrate is often treated with octyltrichlorosilane (OTS $)^{38,163,165}$ or parasexiphenyl $(p-6 \mathrm{p})^{165}$ as it has been demonstrated that Pc molecules tend to grow larger domains on OTS or $p$-6p modified substrates. This leads to reduced grain boundaries, thereby enhancing charge transfer mobility $(\mu)$ and thus better device performance. ${ }^{166-168}$ With respect to the insulating layer, to ensure sufficient charge carriers are present at the interface when a gate voltage is applied, a high dielectric strength material is necessary. While some polymers such as polymethyl methacrylate (PMMA) ${ }^{169}$ have been reported, silicon dioxide $\left(\mathrm{SiO}_{2}\right)$ is by far the most commonly employed insulator. Given MPcs can act as either ptype or n-type semiconductors (depending on the choice of central atom and functionalisation of the Pc backbone, vide
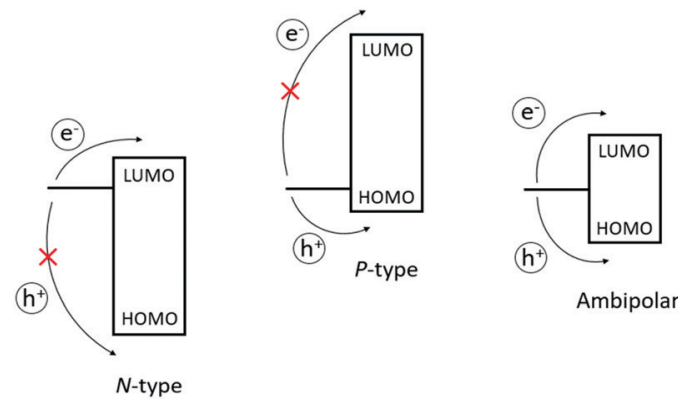

Fig. 7 The compatible relationship between the work function of S/D electrodes and the HOMO/LUMO of the semiconductor material.

infra), variation in S/D electrodes is common. For the purpose of achieving sufficient injection efficiency, the work function of electrodes should be compatible with the energy levels of the frontier molecular orbitals of the semiconductor (Fig. 7), and is therefore highly dependent on the active material. For OFETs with p-type organic semiconductors as the active channel material, high work function metals such as silver $(\sim-4.7 \mathrm{eV})$, gold $(\sim-5.1 \mathrm{eV})$, and platinum $(\sim-5.6 \mathrm{eV})$ are often employed as the S/D electrodes, as their work functions are comparable to the HOMO of most of p-type channel materials (usually from -4.9 to $-5.5 \mathrm{eV}$ ).$^{170}$ On the other hand, in order to match the LUMO of n-type channel materials (usually from -3 to $-4.5 \mathrm{eV}$ ) and achieve efficient charge injection, low work function metals such as calcium $(\sim-2.87 \mathrm{eV})^{171}$ are also used in OFET devices. In some cases, using asymmetric electrodes, e.g., $\mathrm{Au}$ electrode for hole injection and a $\mathrm{Ca}$ electrode $^{172}$ for electron injection in the same device, leads to ambipolar behaviour for semiconductors.

3.1.2 OFET performance and characterisation. The following three parameters are integral to the evaluation of active materials in OFETs. Perhaps most significant is the charge transfer mobility $\left(\mu, \mathrm{cm}^{2} \mathrm{~V}^{-1} \mathrm{~s}^{-1}\right)$, which quantifies the average charge carrier drift velocity per unit electric field. ${ }^{159}$ Another key parameter is the threshold voltage $\left(V_{\mathrm{T}}, \mathrm{V}\right)$ that represents the minimum gate-tosource voltage required to induce current between the S/D terminals. And finally, the on/off current ratio $\left(I_{\text {on }} / I_{\text {off }}\right)$, which is the ratio of the drain current in the on-state compared to that in the off-state and is typically reported as $10^{x}(x=1,2,3, \ldots){ }^{153}$ In general, high $\mu$, low $V_{\mathrm{T}}$ and large on/off current ratio are favourable for high-performing OFETs. Typical output curves of p-type, n-type and ambipolar OFETs are shown in Fig. 8. The relationship
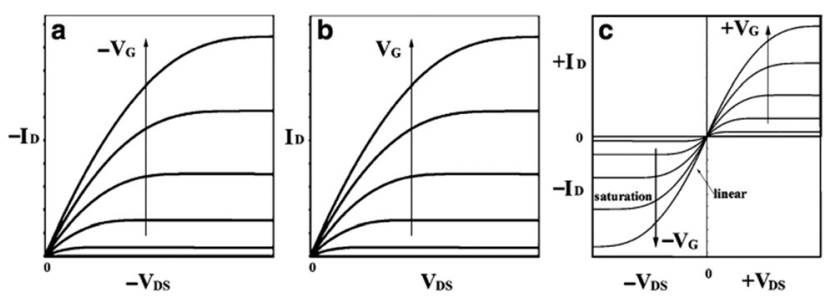

Fig. 8 Schematic diagram of current-voltage characteristics of (a) $p$ type, (b) n-type, and (c) ambipolar OFET device. Reprinted by permission from Springer Nature. 156 Copyright 2010. 
between drain-source current $\left(I_{\mathrm{D}}\right)$ and the voltage in the linear (1) and saturated (2) regions can be describes by the equations below:

$$
\begin{gathered}
I_{\mathrm{D}}=\frac{W}{L} \mu C_{\mathrm{i}}\left(V_{\mathrm{G}}-V_{\mathrm{T}}\right) V_{\mathrm{DS}} \\
I_{\mathrm{D}}=\frac{W}{2 L} \mu C_{\mathrm{i}}\left(V_{\mathrm{G}}-V_{\mathrm{T}}\right)^{2}
\end{gathered}
$$

where $W$ and $L$ are the channel width and length, respectively (Fig. 6e), and $C_{\mathrm{i}}$ is the capacitance per unit area of the insulating layer.

Apart from $\mu, V_{\mathrm{T}}$, and $I_{\mathrm{on}} / I_{\mathrm{off}}$, the stability is also an important aspect while evaluating the performance of OFET devices. To obtain air-stable and high-performing OFETs, appropriate HOMO or LUMO energy levels of the active material is required. The energy of the HOMO $\left(E_{\text {HOMO }}\right)$ for p-type organic semiconductors is usually in the range of -4.9 to $-5.5 \mathrm{eV}$, which should be high enough with respect to the work function of electrode to achieve a low hole injection barrier thereby a low $V_{\mathrm{T}}$, but not too large to avoid being oxidised by air (below $-4.0 \mathrm{eV}$ ). Compared to p-channel counterparts, it is well known that $\mathrm{n}$-channel OFET devices are much more air-sensitive due to the intrinsic instability of organic radical anions under ambient conditions. ${ }^{173}$ As such, most n-type OFETs can only operate under vacuum or an inert atmosphere. Such unacceptable instability towards air, however, can be improved by lowering the energy level of the semiconductor LUMO below $-4.0 \mathrm{eV} .^{174}$ This can be achieved by functionalizing p-type materials with electron-withdrawing groups such as halogen atoms ${ }^{31,175-178}$ or cyano groups, ${ }^{179-182}$ thereby efficiently converting them into n-type semiconductors. Alternatively, introducing pyrazine into the framework of conjugated molecules not only maintains molecular planarity but also decreases the $E_{\text {Hомо }}$ and $E_{\mathrm{LUMO}}$, thereby increasing air stability and electron injection affording n-channel materials. ${ }^{183}$ Inclusion of a six-membered imide ring into aromatic diimides can also lead to potential n-type semiconducting materials with promising air stability. ${ }^{173}$ Interestingly, in some reports of metal phthalocyanines as the active layer in OFETs, the transition from unipolar n-type to ambipolar $^{38}$ or even to p-type semiconductor ${ }^{171}$ was observed, with the p-type conduction increasing after exposing the device to air for several minutes. That behaviour is potentially due to oxygen in air acting as an electron acceptor from the central ion, thereby creating holes in some molecules. ${ }^{38}$ Apart from that, a series of processing parameters including the processing technique (e.g., solution processing, thermal vapor deposition), substrate temperature, annealing, etc. can also influence OFET performance by affecting thin film morphology. Studies of the impact of these parameters on the performance of MPc-based OTFTs has been summarised by Bender, Lessard and co-workers in detail in their review article. ${ }^{21}$

3.1.3 The application of phthalocyanines in OFETs. As mentioned earlier, MPcs have been explored as the active semiconducting layer in OFETs due to their excellent stability and unique optoelectronic properties. ${ }^{21,31}$ The synergistic effects between many transition metal ions and the unsubstituted Pc framework has led to high hole mobilities observed for MPcs, thereby rendering these ideal building blocks as intrinsic p-type organic semiconductors in OFETs. Notably, field-effect mobilities for divalent copper ${ }^{184}$ and zinc ${ }^{185}$ complexes (MPc; $\mathrm{M}=\mathrm{Cu}$ and $\mathrm{Zn}$ ) have been achieved with values around $10^{-1} \mathrm{~cm}^{2} \mathrm{~V}^{-1} \mathrm{~s}^{-1}$, while those for tetravalent titanium ${ }^{186}$ and vanadium oxides ${ }^{187}(\mathrm{O}=\mathrm{MPc}$; $\mathrm{M}=\mathrm{V}$ and $\mathrm{Ti}$ ) have been reported in the range of $1-10 \mathrm{~cm}^{2} \mathrm{~V}^{-1} \mathrm{~s}^{-1}$; some of the highest for p-type organic semiconductors within this class of molecules. As for n-type organic semiconductors, the portfolio of MPcs exhibiting this type of behaviour with transition metal ions is substantially less. In order to activate charge injection, transition metal complexes generally require the introduction of strong electron-withdrawing groups along the Pc framework to drop the energy level of the LUMO. ${ }^{31}$ For example, the perfluorination of copper phthalocyanine (i.e., $\mathrm{Cu}(\mathrm{F}){ }_{16} \mathrm{Pc}$ ) reverts the nature of the unsubstituted hole carrier to afford the best n-type field-effect $\mu$ reported for transition metal Pcs of $0.11 \mathrm{~cm}^{2} \mathrm{~V}^{-1} \mathrm{~s}^{-1}{ }^{185}$

While these $\mu$ s are comparable to devices utilizing benchmark organic semiconductors like pentacene, improvements on overall device performance for these systems is limited from a molecular design approach. A caveat amongst many MPcs with divalent transition metal centres is, for the most part, the lack of tuneable substituents bound to the central ion, which can be used to manipulate the solid-state packing in particular. In general, divalent MPcs tend to assemble in edge-to-face herringbone motifs, reducing $\pi$-orbital overlap and consequentially leading to moderate charge mobilities. Conversely, when these substituents are present, the axial ligands can direct MPcs into face-to-face $\pi$-stacking assemblies, which in turn can strengthen pathways for charge transport. ${ }^{31,32,162,188,189}$

To reap the benefits provided from axial functionalities, attention has been drawn towards main-group Pcs, as a range of stable oxidation states can be accessed from these elements. Trivalent and tetravalent main-group Pcs are in possession of one and two chemical handles, respectively, that can be easily modified for tuning of the material properties. Moreover, higher valencies and greater electronegativities found for many of the p-block elements has been shown to intrinsically affect the nature of the organic semiconductor, from which unipolar n-type and ambipolar behaviours have been observed for unsubstituted Pc complexes. In this section, we provide a view of the OFET performances for devices fabricated with main-group Pcs of groups 13 (B, Al, Ga and $\mathrm{In}$ ) and 14 ( $\mathrm{Si}, \mathrm{Ge}, \mathrm{Sn}$, and $\mathrm{Pb}$ ). Interestingly, there are currently no reports of main-group Pcs with thallium or group 15 elements in the application of OFETs, to the best of our knowledge, despite their chemistry being established.

\subsection{Group 13 phthalocyanines in OFETs}

Key parameters from the performances of OTFTs fabricated from group 13 main-group Pcs have been tabulated in Table 1. Among this group, X-BSubPc derivatives have been widely employed as functional materials in OLEDs and OPVs, ${ }^{20,22}$ however, there remains a paucity of research on their role in OFETs. In 2007, Yasuda and Tsutsui reported the fabrication of OTFT devices using 
Table 1 Field-effect performances for group 13 main-group phthalocyanines in organic thin-film transistors

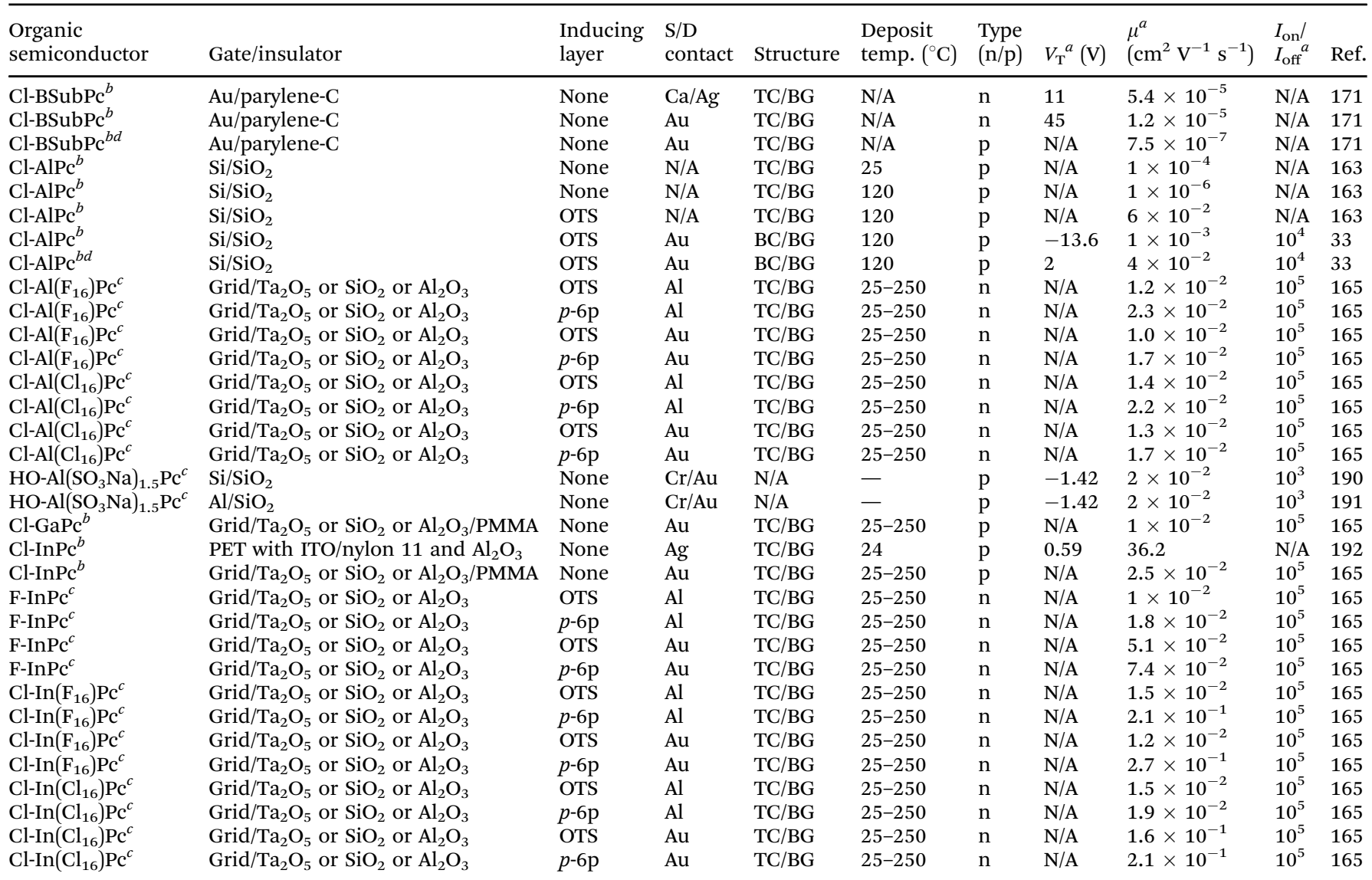

${ }^{a}$ S/D: source and drain electrodes; $\mu$ : best reported carrier (hole for p-channel, electron for n-channel) mobility; $V_{\mathrm{T}}$ : best reported threshold voltage; $I_{\text {on }} / I_{\text {off: }}$ on/off current ratio. ${ }^{b}$ Commercially available. ${ }^{c}$ Prepared in the lab. ${ }^{d}$ Performed in air.

Cl-BSubPc within the active layer. ${ }^{171}$ Metal calcium was utilised for the S/D electrodes with an Ag overlayer, as its low work function reduces electron injection barriers. OFETs, with Cl-BSubPc deposited by vacuum sublimation, exhibited n-channel behaviour with an electron $\mu$ of $5.4 \times 10^{-5} \mathrm{~cm}^{2} \mathrm{~V}^{-1} \mathrm{~s}^{-1}$ and $V_{\mathrm{T}}$ of $11 \mathrm{~V}$. For reference, devices were also constructed using $\mathrm{Au}$ for the S/D electrodes, which showed a drop in the mobility $(\mu=1.2 \times$ $\left.10^{-5} \mathrm{~cm}^{2} \mathrm{~V}^{-1} \mathrm{~s}^{-1}\right)$ and rise in the threshold voltage $\left(V_{\mathrm{T}}=45 \mathrm{~V}\right)$. At the time, the reference OFET with Au S/D electrodes showed a curious ambipolar behaviour when expose to air for a few minutes with a field-effect hole $\mu$ reaching $7.5 \times 10^{-7} \mathrm{~cm}^{2} \mathrm{~V}^{-1} \mathrm{~s}^{-1}$; however, since then, this type of charge carrier $\mu$ is well accepted in X-BSubPcs, as shown in their fabrication into OPVs. ${ }^{22}$

Apart from this work, Bender and co-workers investigated the basic electron mobilities of a series of fluorinated phenoxy BSubPcs (i.e., ( $\left.\mathrm{F}_{5} \mathrm{PhO}\right)-\mathrm{BSubPc},(\mathrm{PhO})-\mathrm{B}(\mathrm{F})_{16} \mathrm{SubPc}$, and $\left(\mathrm{F}_{5} \mathrm{PhO}\right)-$ $\left.\mathrm{B}(\mathrm{F})_{16} \mathrm{SubPc}\right)$ using admittance spectroscopy. ${ }^{193}$ At high electric fields, mobilities reached approximately $10^{-4} \mathrm{~cm}^{2} \mathrm{~V}^{-1} \mathrm{~s}^{-1}$, which are higher than that reported for Cl-BSubPcs. Although these mobilities were not determined for OTFTs, but rather sandwiched between two electrodes perpendicular to the substrate, investigations into the axial ligands in X-BSuBPc warrants further attention to improve OTFT performances based on these systems.
Cl-AlPc, a nonplanar and pyramid-like trivalent phthalocyanine, has been used as in the semiconductor layer of OFET devices in many reports. Compared to the most commonly used planar divalent Pcs such as CuPc, Cl-AlPc forms a face-to-face $\pi$-stacked structure that leads to more-efficient $\pi$-orbital overlap, facilitating charge carrier transport. ${ }^{163}$ Recently, Boileau et $a{ }^{33}{ }^{33}$ reported the impact of environmental pressure and operating temperature on charge transport and electrical stability of p-type BC/BG OTFTs based on Cl-AlPc semiconductor layer. The hole $\mu$ increased from $0.001 \mathrm{~cm}^{2} \mathrm{~V}^{-1} \mathrm{~s}^{-1}$ in vacuum to $0.04 \mathrm{~cm}^{2} \mathrm{~V}^{-1} \mathrm{~s}^{-1}$ in air, indicating that the oxygen present under ambient conditions coordinates to the surface Cl-AlPc metal centres, which will act as an electron acceptor/trap and increase positive charge carrier density in the bulk film as a result. ${ }^{33,171}$ Fig. 9 shows how hole $\mu$ changes with $V_{\mathrm{GS}}$ at different device testing temperatures under either vacuum $\left(\mathrm{a}, 25-150{ }^{\circ} \mathrm{C}\right)$ or air (b, 25-85 ${ }^{\circ} \mathrm{C}$ ) ambience. In general, the $\mu$ increases with increasing temperature in vacuum, while in air it shows minimal change. Besides, under vacuum, the higher the temperature applied, the lower voltage $\left(V_{\mathrm{T}}\right)$ is required to turn the transistor on. However, this overall shift in curves with increasing temperature $\left(\Delta V_{\mathrm{T}}\right)$ is less obvious in air. In the same paper, Boileau et al. ${ }^{33}$ also investigated five other divalent transition-metal Pcs, including $\mathrm{ZnPc}, \mathrm{MgPc}$, FePc, CoPc and CuPc. Fig. 10 illustrates $\Delta V_{\mathrm{T}}$ and percentage 

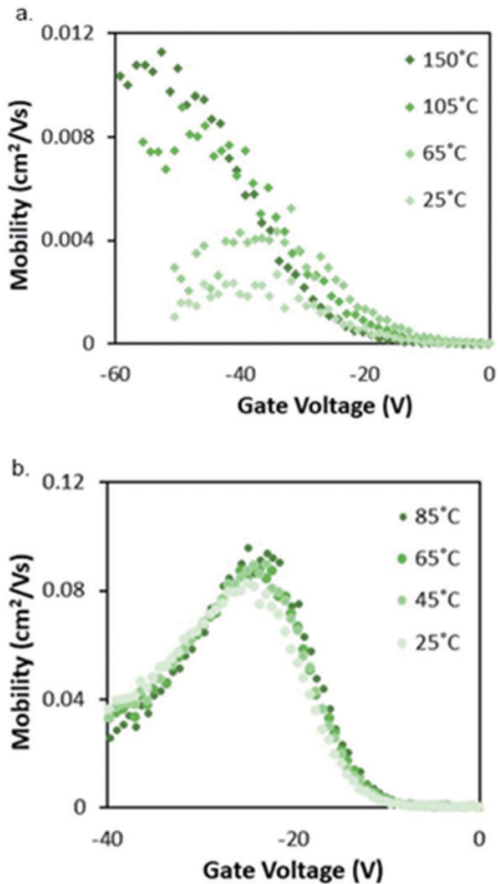

Fig. 9 Characterisation of Cl-AIPc OTFTs. (a) $V_{\text {GS }} v s$. $\mu$ curves at temperatures ranging from $25{ }^{\circ} \mathrm{C}$ to $150{ }^{\circ} \mathrm{C}$ in vacuum. (b) $V_{G S} v s$. $\mu$ curves at temperatures ranging from $25^{\circ} \mathrm{C}$ to $85^{\circ} \mathrm{C}$ in air. Reproduced from ref. 33 with permission from The Royal Society of Chemistry.

changes in $\mu$ of different MPcs. The result indicates that divalent MPcs show generally greater changes in $\mu$ and $V_{\mathrm{T}}$ in performance with temperature by comparison with Cl-AlPc. In other words, Cl-AlPc film has more air-stable electrical properties. This is attributed to its distinct film morphologies with larger grain sizes and higher surface roughness, leading to lower surface area to volume ratios and thus reducing the access of ambient gases to the overall volume, based on the atomic force microscope (AFM) results (Fig. 11).

As previously mentioned, the semiconductor layer can be deposited using different approaches. Since most MPcs have poor solubility, MPc based OFETs are commonly fabricated by vacuum evaporation. To develop a device using solution processing, Glezos and co-workers synthesised water-soluble aluminium complexes by sulfonating unsubstituted HO-AlPc with fuming sulfuric acid. ${ }^{190,191}$ The crude product was a mixture of mono-, $\mathrm{di}^{-}$, tri- and tetra-sulfonated isomers of $\mathrm{HO}-\mathrm{Al}\left(\mathrm{HO}_{3} \mathrm{~S}\right)_{m} \mathrm{Pc}$ ( $m=1-4)$, which was separated by column liquid chromatography, and subsequently treated with $\mathrm{NaOH}$ to afford their fully deprotonated sodium salts. Thin films of $\mathrm{HO}-\mathrm{Al}\left(\mathrm{NaO}_{3} \mathrm{~S}\right)_{m} \mathrm{Pcs}$ were analysed by X-ray photoelectron spectroscopy, from which the atomic ratios of the elements detected on the surface of the spin-casted material indicated a chemical composition reflecting that of $\mathrm{HO}-\mathrm{Al}\left(\mathrm{NaO}_{3} \mathrm{~S}\right)_{1.5} \mathrm{Pcs}$. This was believed to arise from the atmospheric exposure upon processing the material onto the substrate. p-Channel OFET devices based on $\mathrm{HO}-\mathrm{Al}\left(\mathrm{NaO}_{3} \mathrm{~S}\right)_{1.5} \mathrm{Pcs}$ exhibited field-effect mobilities of $0.02 \mathrm{~cm}^{2} \mathrm{~V}^{-1} \mathrm{~s}^{-1}, V_{\mathrm{T}}$ of $-1.42 \mathrm{~V}$ and $\sim 10^{3}$ current on/off ratios.
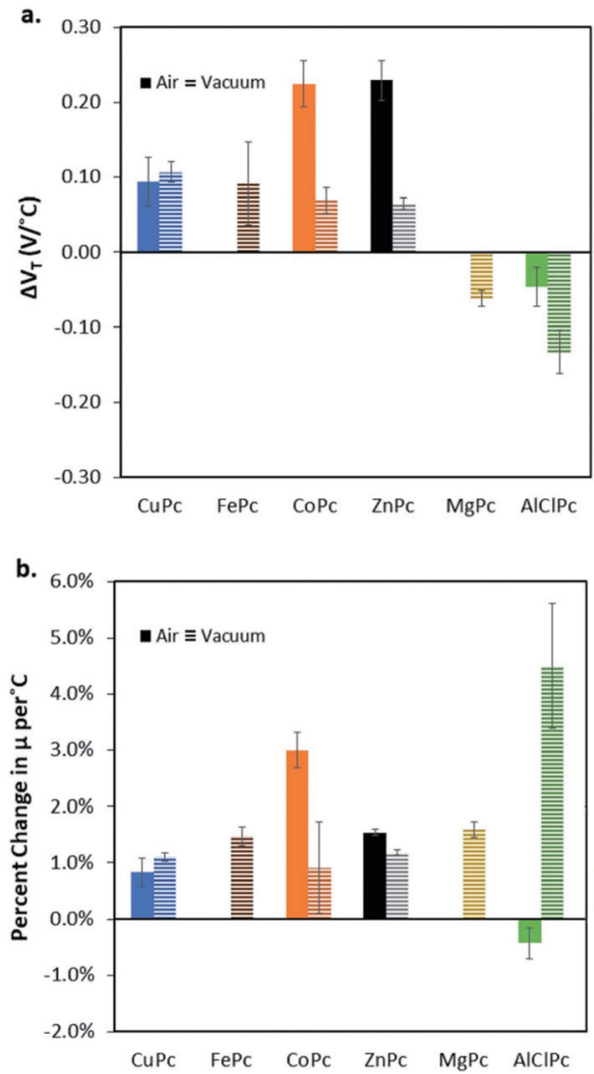

Fig. 10 (a) Change in threshold voltage per degree celsius, $\left(V_{T} /{ }^{\circ} \mathrm{C}\right)$ within the characterised temperature range $\left(25^{\circ} \mathrm{C}\right.$ to $85^{\circ} \mathrm{C}$ for air and $25^{\circ} \mathrm{C}$ to $150^{\circ} \mathrm{C}$ for vacuum) for each phthalocyanine material (bule: CuPc; brown: FePc; orange: CoPc; black: ZnPc; yellow: MgPc; green: Cl-AlPc) characterised in BC/BG OTFT under air (solid bars), and vacuum (horizontal line bars). (b) \% change in hole mobility, $\mu$, compared to baseline at $25^{\circ} \mathrm{C}$ per ${ }^{\circ} \mathrm{C}$. Materials that did not function in air have no corresponding data (FePc, and $\mathrm{MgPc}$ ). Reproduced from ref. 33 with permission from The Royal Society of Chemistry.

In 2011, Chi and co-workers investigated the molecular packing mode and optoelectronic properties of Cl-AlPc which was utilised as the semiconductor layer in TC/BG OTFT devices fabricated on pure $\mathrm{SiO}_{2}$ substrate at room temperature and $120{ }^{\circ} \mathrm{C}$, and on an OTS-treated surface at $120{ }^{\circ} \mathrm{C} .{ }^{163}$ The output and transfer characteristics of these devices are illustrated in Fig. 12, which reveal inferior hole mobilities for the devices fabricated on $\mathrm{SiO}_{2}\left(10^{-4} \mathrm{~cm}^{2} \mathrm{~V}^{-1} \mathrm{~s}^{-1}\right.$ for room temperature, and $10^{-6} \mathrm{~cm}^{2} \mathrm{~V}^{-1} \mathrm{~s}^{-1}$ for $120{ }^{\circ} \mathrm{C}$ ) compared to that of devices employing OTS-modified substrates $\left(0.06 \mathrm{~cm}^{2} \mathrm{~V}^{-1} \mathrm{~s}^{-1}\right.$ for $120{ }^{\circ} \mathrm{C}$ ). This difference in device performance is related to the molecular orientation of the molecules on the three substrates. As shown in Fig. 13c, when Cl-AlPc molecules are depositing on an OTS-modified surface, they align with an inclination angle of $18.2^{\circ}$ with respect to the surface normal, resulting in continuous and flat films. Compared with random or face-on molecular orientations that were formed on the $\mathrm{SiO}_{2}$ surface (Fig. 13a and b), this edge-on orientation is much more favourable for in-plane charge transport due to the reduced grain boundary and the consistency between the chargetransport direction and the $\pi$-stacking direction. ${ }^{163}$ It can 

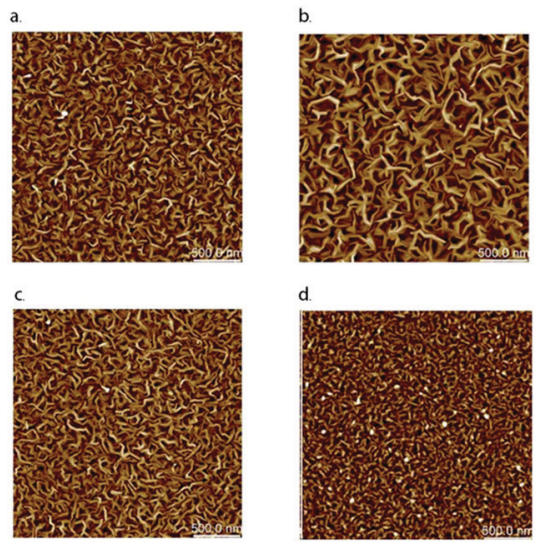

d.
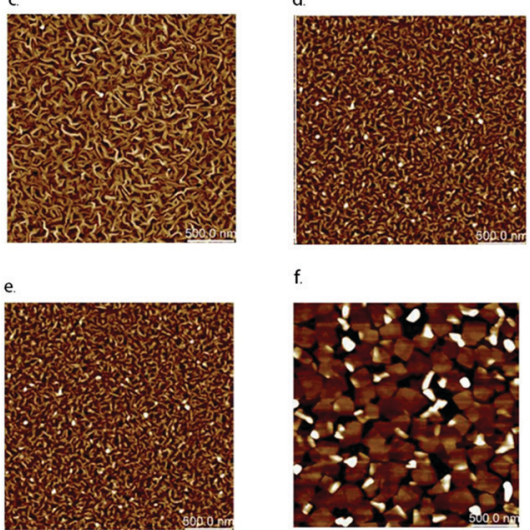

f.

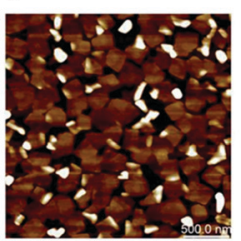

Fig. 11 AFM images $(2.5 \mathrm{~mm} \times 2.5 \mathrm{~mm}$ ) of (a) CuPc (b) FePc (c) CoPc (d) ZnPc (e) $\mathrm{MgPc}(\mathrm{f}) \mathrm{Cl}$-AIPc deposited on heated silicon substrates. Reproduced from ref. 33 with permission from The Royal Society of Chemistry.
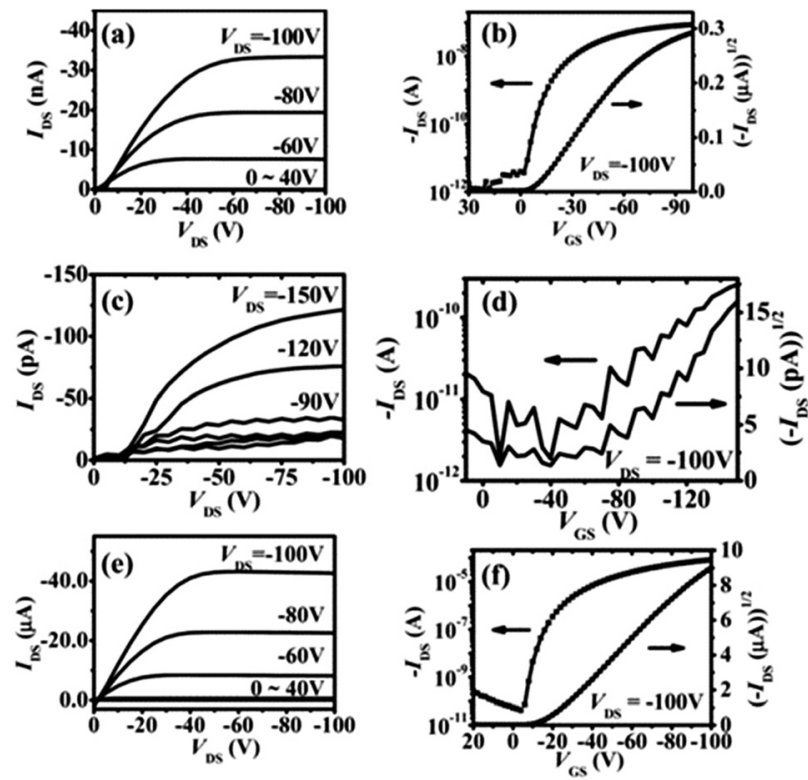

Fig. 12 Output and transfer curves of devices with Cl-AlPc active layer fabricated under different conditions: ( $a$ and b) pure $\mathrm{SiO}_{2}$ surface at room temperature; (c and d) pure $\mathrm{SiO}_{2}$ surface at $120{ }^{\circ} \mathrm{C}$; (e and f) OTS-modified surface at $120{ }^{\circ} \mathrm{C}$. The image is reprinted with permission from ref. 163. Copyright 2011, Wiley-VCH.

therefore be concluded that high-performance OTFTs can be obtained by tuning the surface properties and substrate temperature to control the growth of the film with appropriate packing mode.

Hexadecafluoro- and hexadecachloro-substituted Cl-AlPcs and Cl-InPcs in OTFTs have also been reported. ${ }^{165}$ Those derivatives exhibited n-type behaviour with varied electron mobilities,
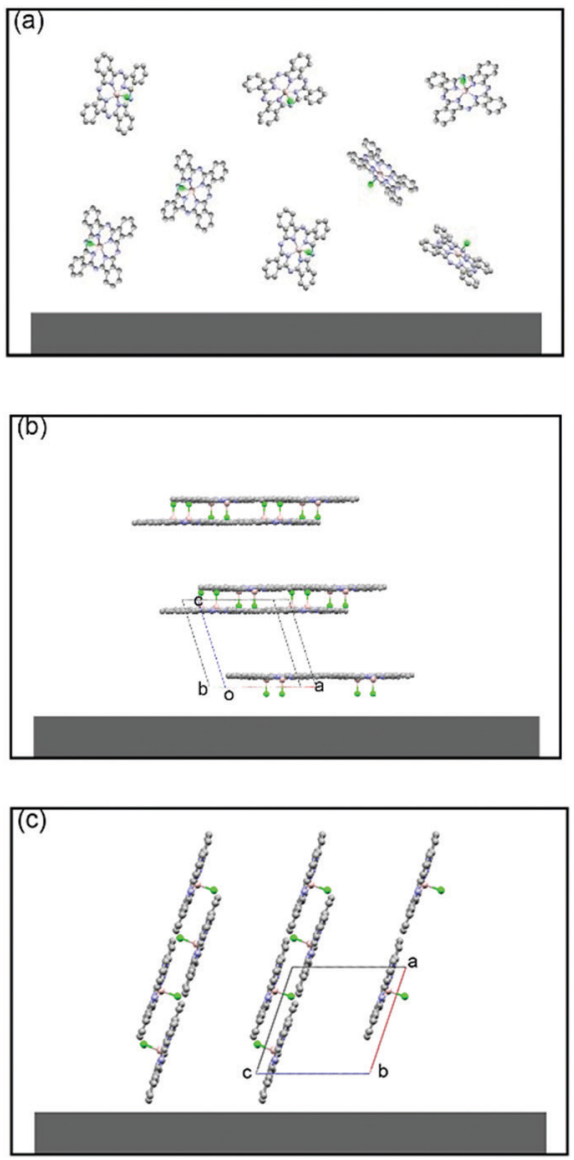

Fig. 13 Schematic molecular packing of a Cl-AIPC (CCDC: 1134071) film fabricated on a pure $\mathrm{SiO}_{2}$ substrate at room temperature (a) and $120{ }^{\circ} \mathrm{C}(\mathrm{b})$, and on an OTS-modified surface at $120^{\circ} \mathrm{C}$ (c). The image is reprinted with permission from ref. 163. Copyright 2011, Wiley-VCH.

depending on the choice of central ion, S/D electrodes and surface modification layers ( $p-6 p$ or OTS). In addition, the only data regarding $\mathrm{Cl}-\mathrm{GaPc}$ as the semiconductor layer in OFETs was reported in the same article. ${ }^{165}$ The electron $\mu$ was $0.01 \mathrm{~cm}^{2} \mathrm{~V}^{-1} \mathrm{~s}^{-1}$. Other properties such as types of the carriers, the carrier $\mu$, and on/off current ratio of thin-film transistor are listed in Table 1. No more analysis was provided in this article.

Hamui and co-workers prepared a high-performance OFET with a $\mu$ of $36.2 \mathrm{~cm}^{2} \mathrm{~V}^{-1} \mathrm{~s}^{-1}$ and a $V_{\mathrm{T}}$ of $0.59 \mathrm{eV}$ by employing $\mathrm{Cl}$-InPc as a p-type semiconductor and including a bilayer gate dielectric consisting of poly(ethylene terephthalate) (PET) and indium-tin oxide (ITO). ${ }^{192}$ Within a short potential window, the device quickly responded to an increase in the gate voltage to $-5.6 \mathrm{~V}$ resulting in a minimum $\mu$ of $3.2 \mathrm{~cm}^{2} \mathrm{~V}^{-1} \mathrm{~s}^{-1}$. The gate voltage was further increased to $-12 \mathrm{~V}$, from which a second maximum $\mu$ of $5.9 \mathrm{~cm}^{2} \mathrm{~V}^{-1} \mathrm{~s}^{-1}$ was observed. The improved $\mu$ was attributed to the bilayer structure and the ability for Cl-InPc to be an effective hole carrier through the extensive $\pi$-system.

\subsection{Group 14 phthalocyanines in OTFTs}

For group 14 main-group Pcs, their performances in OTFTs have been tabulated in Table 2. Tetravalent MPcs with group 
Table 2 Field-effect performances for group 14 main-group phthalocyanines in organic thin-film transistors

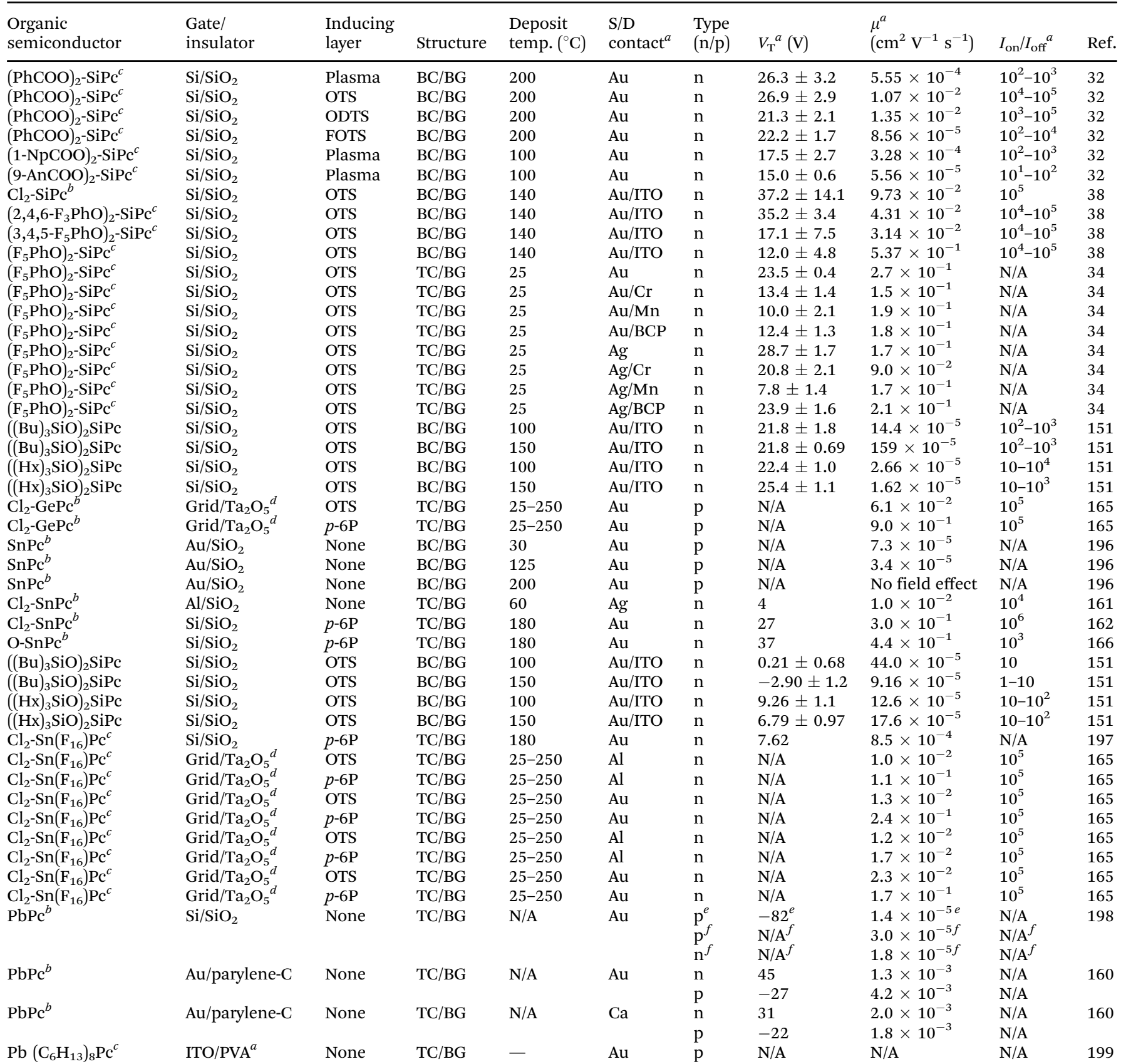

${ }^{a} \mathrm{~S} / \mathrm{D}$ : source and drain electrodes; $\mu$ : best reported carrier (hole for p-channel, electron for n-channel) mobility; $V_{\mathrm{T}}$ : best reported threshold voltage; $I_{\mathrm{on}} / I_{\text {off: }}$ on/off current ratio; PVA: polyvinyl alcohol. ${ }^{b}$ Commercially available. ${ }^{c}$ Prepared in the lab. ${ }^{d}$ or $\mathrm{SiO}_{2}$ or $\mathrm{Al}_{2} \mathrm{O}_{3} .{ }^{e} \mathrm{Performed}$ in dark. ${ }^{f}$ Performed in light.

14 elements are of increasing interest in the field of organic electronics due in part to the presence of two axial substituents that can be modified. Not only can these be tailored to enhance solubility, but they can also be functionalised to augment the solid-state arrangement and thin film packing of the molecules. Furthermore, recent studies have demonstrated that $\mathrm{X}_{2}$-SiPcs exhibit promising n-type mobilities, offering an alternative to the widely employed fullerene base acceptors. ${ }^{194,195}$

In 2018, Melville et al. reported $\mathrm{X}_{2}$-SiPcs in OTFT application for the first time. ${ }^{32}$ Specifically, they investigated the use of a series of
$\mathrm{X}_{2}$-SiPcs axially functionalised with carboxylates attached to aromatic rings as active materials in OTFTs (Fig. 14a-c). Encouragingly, all derivatives exhibited n-channel behaviour and revealed the importance of the axial substituents on the thin film morphology. The authors noted that an increase in the steric bulk of the aromatic axial substituents was accompanied by a decrease in both the electron $\mu$ and $I_{\mathrm{on}} / I_{\text {off }}$ ratio. The same tendency was also observed with the $V_{\mathrm{T}}$. The structures of the molecules as determined using single crystal X-ray diffraction are shown in Fig. 14. Notably (PhCOO) ${ }_{2}$-SiPc displays the $2 \mathrm{D}$ arrangement of $\pi-\pi$ 
(a)

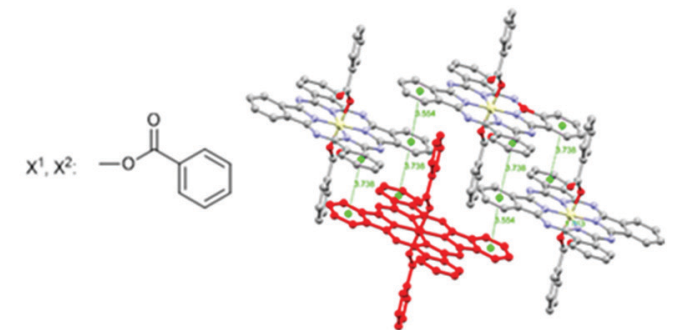

(b)

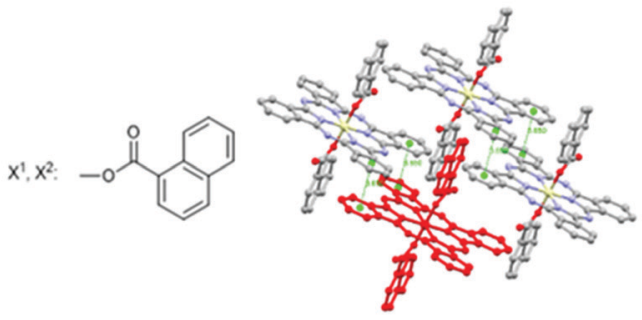

(c)
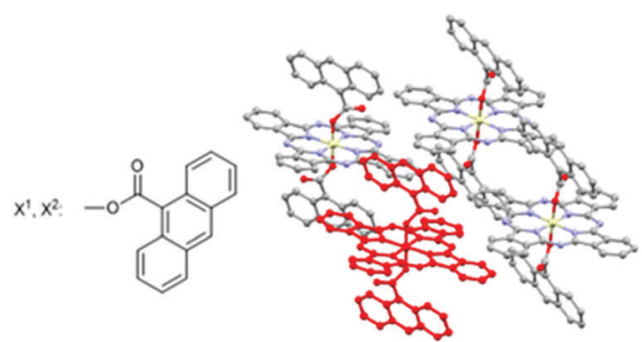

Fig. 14 Chemical structures and solid-state arrangement of three $\mathrm{X}_{2}-\mathrm{SiPc}$ axially substituted with carboxylates. Molecular overlap with a centroidcentroid distance $<4 \AA$ are indicated with dotted green lines. Reproduced from ref. 32 with permission from The Royal Society of Chemistry.

stacking pathways while (1-NpCOO) ${ }_{2}$-SiPc does not, despite (1$\mathrm{NpCOO})_{2}$-SiPc having the closest $\pi-\pi$ distance. On the other hand, the structure of (9-AnCOO) $)_{2}$-SiPc possesses little $\pi-\pi$ overlap, which may explain why (PhCOO) $)_{2}$-SiPc has the highest $\mu$ among those three derivatives. Furthermore, the performance of devices using $(\mathrm{PhCOO})_{2}$-SiPc was systematically probed through modifications to the dielectric surface treatments. It was observed when trichloro(octyl)silane (OTS) and trichloro(octadecyl)silane (ODTS) were employed, mobilities were enhanced, while the inverse was observed with trichloro( $1 H, 1 H, 2 H, 2 H$-perfluorooctyl)silane (FOTS).

Following that initial report, OTFTs were studied employing SiPcs axially functionalised with pentafluorophenoxy $\left(\left(\mathrm{F}_{5} \mathrm{PhO}\right)_{2^{-}}\right.$ SiPc), 2,4,6-trifluorophenoxy $\left(\left(2,4,6-\mathrm{F}_{3} \mathrm{PhO}\right)_{2}-\mathrm{SiPc}\right.$ and 3,4,5trifluorophenoxy $\left(3,4,5-\mathrm{F}_{3} \mathrm{PhO}\right)_{2}$-SiPc) substituents further revealing the n-type behaviour of SiPcs. ${ }^{38}$ Devices based on $\left(\mathrm{F}_{5} \mathrm{PhO}\right)_{2}$-SiPc possessed the highest electron $\mu$ (up to $0.5 \mathrm{~cm}^{2} \mathrm{~V}^{-1} \mathrm{~s}^{-1}$ ), and currently holds the highest record for all n-type MPcs, along with the lowest $V_{\mathrm{T}}$ averaging around $12.0 \mathrm{~V}$. Conversely, $\mathrm{Cl}_{2} \mathrm{SiPc}$ based devices exhibited the highest $V_{\mathrm{T}}$ (up to $37 \mathrm{~V}$ ) and relatively low $\mu_{\mathrm{e}}$. These results reveal the importance of the substituents and suggest the addition of the fluorinated phenoxy pendant groups induce $\pi-\pi$ overlap. The authors also investigated the effect of characterisation atmosphere on device performance, with all OTFTs characterised at both positive and negative $V_{\mathrm{Gs}}$ and $V_{\mathrm{DS}}$ under
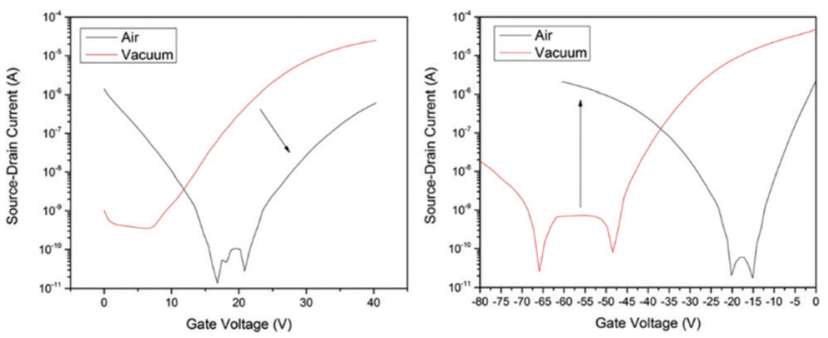

Fig. 15 Sample transfer curves for OTFTs using $\left(\mathrm{F}_{5} \mathrm{PhO}\right)_{2}-\mathrm{SiPc}$ as the active layer when operated in the electron accumulation region (left) and hole accumulation region (right) and characterised either under vacuum or in air. The image is reprinted with permission from 38. Copyright 2019, Wiley-VCH.

vacuum and air conditions. As an example, Fig. 15 shows a sample transfer curve under each condition for material $\left(\mathrm{F}_{5} \mathrm{PhO}\right)_{2}$-SiPc. The results, listed in Table 3, reveal an interesting phenomenon of increased p-type charge transfer while transferring devices from vacuum to air, except $\mathrm{Cl}_{2}$-SiPc, which did not show a significant field effect for holes under any condition. This change may be attributed to oxygen in air acting as an electron acceptor from the central metal atom, creating holes in some molecules.

To enhance device performance and reduce the injection barrier between the organic semiconductor and contacts, Melville et al. have introduced either an electron dopant layer (bathocuproine, BCP) or low-work-function metals $(\mathrm{Mn} / \mathrm{Cr}$ ) between the high work-function electrodes ( $\mathrm{Au}, \mathrm{Ag})$ and the $\left(\mathrm{F}_{5} \mathrm{PhO}\right)_{2}$-SiPc semiconductor layer. ${ }^{34}$ The device structure is shown in Fig. 16, and the saturation region properties are shown in Fig. 17. This study reveals the presence of these interlayers reduces $V_{\mathrm{T}}$, contact resistance and saturation region $\mu$, while improving the linear region mobility (Table 3). The same treatment and characterisation methods were also applied to their tin counterparts, namely $\left(\mathrm{F}_{5} \mathrm{PhO}\right)_{2}$-SnPc and $\left(2,4,6-\mathrm{F}_{3} \mathrm{PhO}\right)_{2}$-SnPc. $^{34}$ The results of this study indicate that $\mathrm{Mn}$ and $\mathrm{Cr}$ interlayers do not strongly affect performance, while BCP can increase the off-current provided the entire organic semiconductor film is covered. These results were attributed to the larger Sn atom, which has a higher propensity for interaction with BCP than SiPc.

$\mathrm{X}_{2}$-SnPcs are widely used as n-type semiconductors due to the relatively high electronegativity of tetravalent $\operatorname{tin},{ }^{166}$ and the closely $\pi$-stacked intermolecular motifs that they formed in crystals. $^{127}$ For example, Giri and co-workers reported that vacuum-deposited $\mathrm{Cl}_{2}$-SnPc OFETs exhibited good n-channel behaviour with electron $\mu$ of $0.01 \mathrm{~cm}^{2} \mathrm{~V}^{-1} \mathrm{~s}^{-1}$, low $V_{\mathrm{T}}$ of $4 \mathrm{~V}$, current on/off ratio of $10^{4}$, and high operation stability with no hysteresis when tested in low vacuum condition. ${ }^{161}$ Yan and co-workers reported a high-performance air-stable n-type OTFT device based on $\mathrm{Cl}_{2}$-SnPc deposited on a para-sexiphenyl modified substrate with the electron $\mu$ of $0.30 \mathrm{~cm}^{2} \mathrm{~V}^{-1} \mathrm{~s}^{-1}$ and the current on/off ratio of $10^{6}{ }^{162}$ After storage in air for 45 days, this device still has a $\mu$ up to $0.12 \mathrm{~cm}^{2} \mathrm{~V}^{-1} \mathrm{~s}^{-1}$ which indicated its excellent stability. Song's group also fabricated another airstable OTFT based on tin phthalocyanine oxide $(\mathrm{O}=\mathrm{SnPc}) .{ }^{166}$ 
Table 3 Mean field-effect mobility $(\mu)$ and threshold voltage $\left(V_{T}\right)$ of OTFTs using $X_{2}$-SiPc as semiconductors deposited at $140{ }^{\circ} \mathrm{C}$ characterised in both vacuum $(P<0.1 \mathrm{~Pa})$ and in air. Results were obtained both in hole accumulation $\left(V_{\mathrm{GS}}, V_{\mathrm{DS}}<0 \mathrm{~V}\right)$ and electron accumulation $\left(V_{\mathrm{GS}}, V_{\mathrm{DS}}>0 \mathrm{~V}\right)$ regions under both environmental conditions. ${ }^{38}$

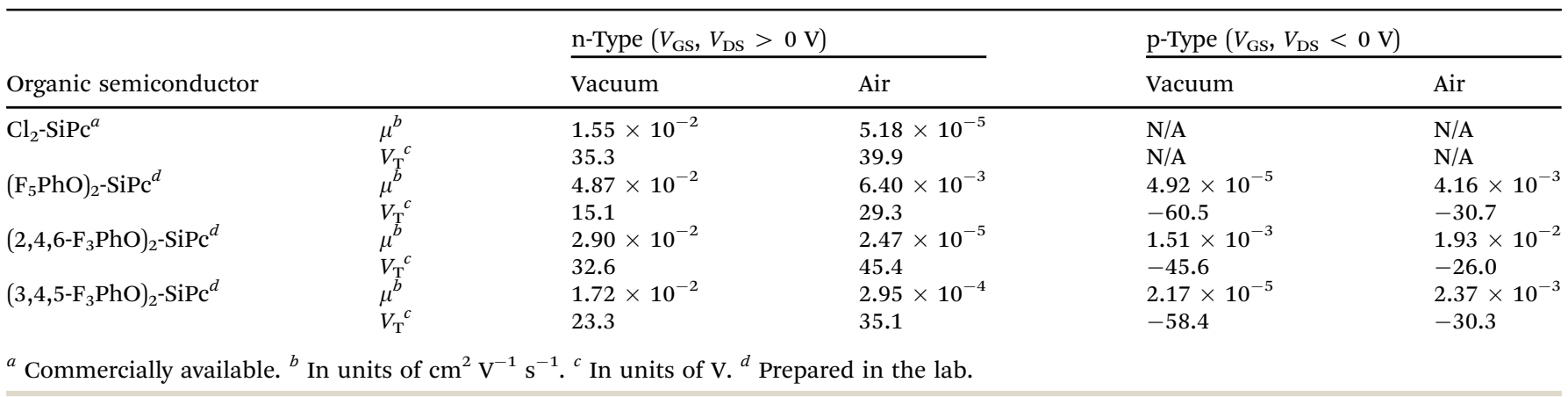

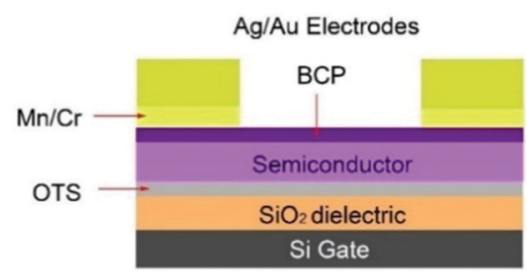

Fig. 16 Device schematic for TC/BG OTFTs with either an electron transport (bathocuproine (BCP)) or low-work-function metal $(\mathrm{Mn} / \mathrm{Cr}$ ) interlayer between the main electrode $(\mathrm{Ag} / \mathrm{Au})$ and organic semiconductor. Reprinted with permission from ref. 34. Copyright 2020, American Chemical Society.
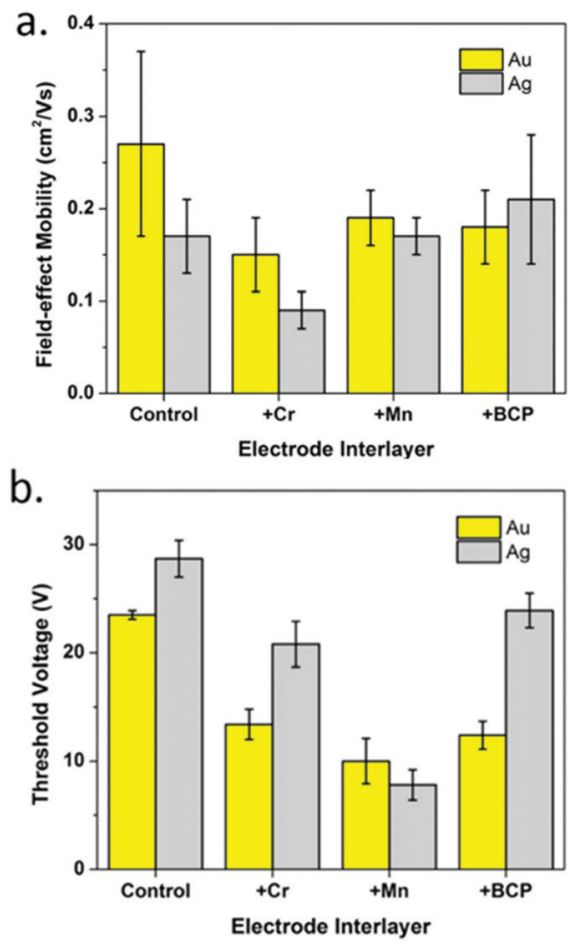

Fig. 17 Saturation region properties for OTFTs using $\left(\mathrm{F}_{5} \mathrm{PhO}\right)_{2}-\mathrm{SiPc}$ as the semiconductor layer with $\mathrm{Au}$ and $\mathrm{Ag}$ electrodes and $\mathrm{Cr}$, Mn, or BCP interlayers: (a) field-effect mobility and (b) threshold voltage. Reprinted with permission from ref. 34. Copyright 2020, American Chemical Society.

An electron $\mu$ of $0.44 \mathrm{~cm}^{2} \mathrm{~V}^{-1} \mathrm{~s}^{-1}$ has been achieved, and it did not obviously change after storage in air for 32 days. The results

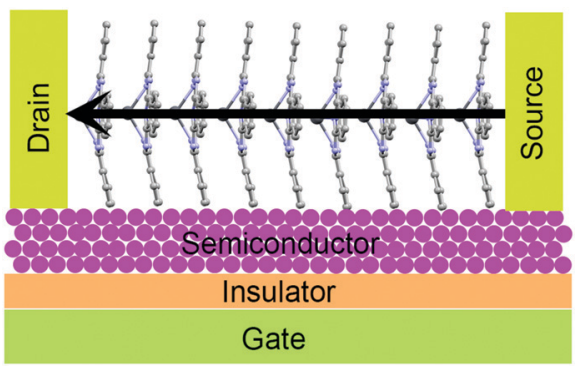

Fig. 18 The favourable molecular orientation of PbPc in OFETs. The arrows indicate the direction of the highest electrical conductivity. Reprinted figure with permission from ref. 164 Copyright a 2012, World Scientific.

reveal that incorporating appropriate electron-withdrawing groups such as chloride and oxygen into $\pi$-conjugated systems is an effective approach to design air-stable n-type semiconductors. The electron mobilities of OTFT devices based on $\mathrm{Cl}_{2}-\mathrm{Sn}(\mathrm{F})_{16} \mathrm{Pc}$ and $\mathrm{Cl}_{2}-\mathrm{Sn}(\mathrm{Cl})_{16} \mathrm{Pc}$ were reported as well. ${ }^{165}$ The OTFTs using $p$-6P modified substrate exhibited approximately 10 times larger $\mu_{\mathrm{e}}$ than that of OTFTs using OTS modified substrate.

Transistor behaviour has also been studied in divalent tin complexes, specifically SnPc. Bao and Lovinger studied the performance of devices with thin films of SnPc vacuum deposited at three temperatures (i.e., $30,125,200{ }^{\circ} \mathrm{C}$ ), from which the material operated as a p-type semiconductor. Average electron mobilities were shown to increase from $30{ }^{\circ} \mathrm{C}$ to $125{ }^{\circ} \mathrm{C}(7.3 \times$ $10^{-5}$ to $3.4 \times 10^{-3} \mathrm{~cm}^{2} \mathrm{~V}^{-1} \mathrm{~s}^{-1}$, respectively) and subsequently exhibited no field-effect when deposition temperatures reached $200{ }^{\circ} \mathrm{C}$. Presumably, better morphological ordering and an enlargement in the size of crystals were attributed to the enhancements in mobilities up to $125{ }^{\circ} \mathrm{C}$, while the presence of large voids appear at higher temperatures.

Reports focusing on GePc derivatives in the application of OFET are less. The only report demonstrates that $\mathrm{Cl}_{2}-\mathrm{GePc}$ showed p-type results in OTFTs, achieving electron mobilities up to 0.06 and $0.09 \mathrm{~cm}^{2} \mathrm{~V}^{-1} \mathrm{~s}^{-1}$ on OTS or $p$-6P modified substrate, respectively. ${ }^{165}$ As for $\mathrm{PbPc}$, a series of devices have been explored. It is known that a parallel charge transport direction is favourable for high-performance OFETs. In the case of PbPc molecules, the highest conductivity is perpendicular to 
the molecular plane as shown in Fig. $18 .{ }^{164}$ Richter and co-workers indicated that an epitaxial-like growth mode of PbPc molecules on reconstructed $\operatorname{GaAs}(001)$ surfaces takes place by Raman spectroscopy, which is an important result for OFETs. ${ }^{164}$ In addition, the relatively low band gap of $\mathrm{PbPc}$ $(1.2 \mathrm{eV})$ makes it a good candidate in the application of ambipolar OFETs. For instance, Yasuda et $a .^{160}$ fabricated OTFT devices based on PbPc semiconductor layer, and both devices with $\mathrm{Au}$ or Ca S/D electrodes showed typical ambipolar characteristics. In the case of $\mathrm{Au}$, the field-effect electron $\mu$ was calculated to be $8.3 \times 10^{-4} \mathrm{~cm}^{2} \mathrm{~V}^{-1} \mathrm{~s}^{-1}$ when the $V_{\mathrm{T}}$ was $31 \mathrm{~V}$, while the hole $\mu$ was calculated to be $7.1 \times 10^{-4} \mathrm{~cm}^{2} \mathrm{~V}^{-1} \mathrm{~s}^{-1}$ when the $V_{\mathrm{T}}$ was $-58 \mathrm{~V}$. In the case of $\mathrm{Ca}$, an electron $\mu$ of $1.3 \times 10^{-3} \mathrm{~cm}^{2} \mathrm{~V}^{-1} \mathrm{~s}^{-1}\left(V_{\mathrm{T}}=36 \mathrm{~V}\right)$ and a hole $\mu$ of $4.7 \times$ $10^{-4} \mathrm{~cm}^{2} \mathrm{~V}^{-1} \mathrm{~s}^{-1}\left(V_{\mathrm{T}}=-60 \mathrm{~V}\right)$ were estimated from saturation currents. After annealing in the glove box for $12 \mathrm{~h}$ at $100{ }^{\circ} \mathrm{C}$, the field-effect mobilities of all the devices increased for both carriers. In addition, Peng et al. ${ }^{198}$ discovered the photoinduced balanced ambipolar transports in PbPc-based OFETs. As reported, $\mathrm{PbPc}$ semiconductor initially behaves $\mathrm{p}$-channel unipolar in the dark due to the significantly lower energy barrier for hole injection $(0.1 \mathrm{eV})$ compared to the energy barrier for electron injection $(1.2 \mathrm{eV})$. However, the electron $\mu$ increased to $1.8 \times 10^{-5} \mathrm{~cm}^{2} \mathrm{~V}^{-1} \mathrm{~s}^{-1}$ under illumination at $655 \mathrm{~nm}, 100 \mathrm{~mW} \mathrm{~cm}^{-2}$, which is very close to the value of the hole $\mu$ $\left(3.0 \times 10^{-5} \mathrm{~cm}^{2} \mathrm{~V}^{-1} \mathrm{~s}^{-1}\right)$, as the high electron injection barrier was reduced by light illumination. They attribute this to the reduction in electron potential energy from the downward bend of the HOMO and LUMO of PbPc as a consequence of photo-generated holes accumulated near the source electrode. Subsequently, this reduces the electron injection barrier at the S/D interface. ${ }^{198}$

OFETs based on PbPc derivatives were also reported to be used as non-volatile organic memory device with continuous write-readerase-read switching performance by Mukherjee et al. ${ }^{199}$ The device exhibited p-channel behaviour. The introduction of hexylsubstituents in bay positions, as in $\mathrm{Pb}\left(n-\mathrm{C}_{6} \mathrm{H}_{13}\right)_{8} \mathrm{Pc}$, efficiently improved the solubility of the material, enabling its ready formulation as thin film by spin-coating. As d, reports focusing on GePc derivatives in the application of OFET are less. The only report demonstrates that $\mathrm{Cl}_{2}$-GePc showed p-type results in OTFTs, achieving electron mobilities up to 0.06 and $0.09 \mathrm{~cm}^{2} \mathrm{~V}^{-1} \mathrm{~s}^{-1}$ on OTS or $p$-6P modified substrate, respectively. ${ }^{165}$

\section{Conclusion - outlook}

From what began as a chemical curiosity in the investigative studies by Linstead, metal phthalocyanines have since emerged to become, in our opinion, a paramount building block for the development of OTFTs among other applications. The key to MPcs as intrinsic organic semiconductors is tied to the harmonious interplay between the metal ion and the macroaromatic heterocycle. As can be seen through the recent employment of maingroup Pcs in these devices, there exists an opportunity to systematically control the behaviour of the material without the necessity for exterior functionalisation. This simply can be harnessed through the range of accessible stable oxidation states and electronegativities of the p-block elements, whereas the degree of this synergy is not fully realised in transition metals. With this said, functionalization at the peripheral, bay and axial positions becomes the "icing on the cake" for main-group Pcs, enabling the fine-tuning of the energetics, enhancing intermolecular interactions and controlling self-assembly on a given substrate. This has been clearly demonstrated in recent reports on various silicon phthalocyanines, from which the ligation of fluorinated phenols has led to materials in possession of ambipolarity, air stability, and the highest field-effect mobilities for n-type MPcs.

To take advantage of the attractive features associated with main-group Pcs, considerable attention must be directed to synthetic methodologies in their preparation. The chemistry of main-group Pcs is not new in the slightest; however, unlike transition metals, the relative ease of synthesis becomes increasingly difficult with the introduction of metalloids. This is even more so apparent with non-metals, from which only pentavalent phosphorus has been successfully realized. Despite this, motivation to fabricate OTFTs from MPcs with the relatively unexplored p-block elements has undoubtably steered research efforts towards these challenges. Specifically, for silicon phthalocyanines, derivatisation of the diiminoisoindoline precursor can be readily achieved through the work presented by Brusso and Lessard towards alleviating the strenuous reaction conditions, from which the current benchmark of in n-type MPcs, i.e. $\left(\mathrm{F}_{5} \mathrm{PhO}\right)_{2}$-SiPc, may soon be superseded. On the other hand, inspiration from the works of Kobayashi and earlier pioneers of phosphorus Pcs may soon draw attention towards the first OTFT fabricated with non-metal Pcs. To this end, this review aims to unmask the hidden potential of main-group phthalocyanines as versatile building blocks in organic thin film transistors.

\section{Conflicts of interest}

The authors declare no conflicts of interest.

\section{Acknowledgements}

This work was supported by the University of Ottawa, the Canadian Foundation for Innovation, the National and Engineering Council of Canada. J. L. B. is grateful to the Ontario Ministry of Research and Innovation for an Early Researcher Award.

\section{Notes and references}

1 P. Gregory, J. Porphyrins Phthalocyanines, 2000, 04, 432-437.

2 R. P. Linstead, J. Chem. Soc., 1934, 1016.

3 J. M. Robertson, J. Chem. Soc., 1935, 615.

4 Phthalocyanines, Properties and Applications, ed. C. C. Leznoff and A. B. P. Lever, VCH, Weinheim, Germany, 2012, vol. 1-4.

5 K. Ishii and N. Kobayaski, in The Porphyrin Handbook, ed. K. M. Kadish, K. M. Smith and R. Guilard, Academic Press, New York, 2003, vol. 16, pp. 1-42. 
6 J. Mack and M. J. Stillman, in The Porphyrin Handbook, ed. K. M. Kadish, K. M. Smith and R. Guilard, Academic Press, New York, 2003, vol. 16, pp. 43-116.

7 M. L'Her and A. Pondaven, in The Porphyrin Handbook, ed. K. M. Kadish, K. M. Smith and R. Guilard, Academic Press, New York, 2003, vol. 16, pp. 117-170.

8 A. B. Sorokin, Chem. Rev., 2013, 113, 8152-8191.

9 G. de la Torre, M. Nicolau and T. Torres, Supramolecular Photosensitive and Electroactive Materials, Elsevier, 2001, pp. 1-111.

10 X. Li, B. De Zheng, X. H. Peng, S. Z. Li, J. W. Ying, Y. Zhao, J. D. Huang and J. Yoon, Coord. Chem. Rev., 2019, 379, 147-160.

11 E. W. Y. Wong, C. J. Walsby, T. Storr and D. B. Leznoff, Inorg. Chem., 2010, 49, 3343-3350.

12 W. Zhou and D. B. Leznoff, Chem. Commun., 2018, 54, 1829-1832.

13 D. McKearney, W. Zhou, C. Zellman, V. E. Williams and D. B. Leznoff, Chem. Commun., 2019, 55, 6696-6699.

14 W. Zhou, D. McKearney and D. B. Leznoff, Chem. - Eur. J., 2020, 26, 1027-1031.

15 J. Bartolomé, C. Monton and I. K. Schuller, Magnetism of metal phthalocyanines, Springer, Berlin, Heidelberg, 2014.

16 M. Bouvet, P. Gaudillat and J. M. Suisse, J. Porphyrins Phthalocyanines, 2013, 17, 913-919.

17 G. de la Torre, P. Vázquez, F. Agulló-López and T. Torres, Chem. Rev., 2004, 104, 3723-3750.

18 C. G. Claessens, U. Hahn and T. Torres, Chem. Rec., 2008, 8, 75-97.

19 Functional Phthalocyanine Molecular Materials, ed. J. Jiang, Springer Berlin Heidelberg, Berlin, Heidelberg, 2010, vol. 135.

20 G. E. Morse and T. P. Bender, ACS Appl. Mater. Interfaces, 2012, 4, 5055-5068.

21 O. A. Melville, B. H. Lessard and T. P. Bender, ACS Appl. Mater. Interfaces, 2015, 7, 13105-13118.

22 T. M. Grant, D. S. Josey, K. L. Sampson, T. Mudigonda, T. P. Bender and B. H. Lessard, Chem. Rec., 2019, 19, 1093-1112.

23 B. Verreet, S. Schols, D. Cheyns, B. P. Rand, H. Gommans, T. Aernouts, P. Heremans and J. Genoe, J. Mater. Chem., 2009, 19, 5295.

24 K. V. Chauhan, P. Sullivan, J. L. Yang and T. S. Jones, J. Phys. Chem. C, 2010, 114, 3304-3308.

25 B. H. Lessard, R. T. White, M. Al-Amar, T. Plint, J. S. Castrucci, D. S. Josey, Z. H. Lu and T. P. Bender, ACS Appl. Mater. Interfaces, 2015, 7, 5076-5088.

26 D. S. Josey, S. R. Nyikos, R. K. Garner, A. Dovijarski, J. S. Castrucci, J. M. Wang, G. J. Evans and T. P. Bender, ACS Energy Lett., 2017, 2, 726-732.

27 M. G. Helander, G. E. Morse, J. Qiu, J. S. Castrucci, T. P. Bender and Z. H. Lu, ACS Appl. Mater. Interfaces, 2010, 2, 3147-3152.

28 T. Plint, B. H. Lessard and T. P. Bender, J. Appl. Phys., 2016, 119, 145502.

29 E. Zysman-Colman, S. S. Ghosh, G. Xie, S. Varghese, M. Chowdhury, N. Sharma, D. B. Cordes, A. M. Z. Slawin and I. D. W. Samuel, ACS Appl. Mater. Interfaces, 2016, 8, 9247-9253.

30 A. J. Pearson, T. Plint, S. T. E. Jones, B. H. Lessard, D. Credgington, T. P. Bender and N. C. Greenham, J. Mater. Chem. C, 2017, 5, 12688-12698.

31 L. Li, Q. Tang, H. Li, W. Hu, X. Yang, Z. Shuai, Y. Liu and D. Zhu, Pure Appl. Chem., 2008, 80, 2231-2240.

32 O. A. Melville, T. M. Grant and B. H. Lessard, J. Mater. Chem. C, 2018, 6, 5482-5488.

33 N. T. Boileau, R. Cranston, B. Mirka, O. A. Melville and B. H. Lessard, RSC Adv., 2019, 9, 21478-21485.

34 O. A. Melville, T. M. Grant, K. Lochhead, B. King, R. Ambrose, N. A. Rice, N. T. Boileau, A. J. Peltekoff, M. Tousignant, I. G. Hill and B. H. Lessard, ACS Appl. Electron. Mater., 2020, 2, 1313-1322.

35 G. De La Torre, C. G. Claessens and T. Torres, Chem. Commun., 2007, 2000-2015.

36 C. G. Claessens, U. Hahn and T. Torres, Chem. Rec., 2008, 8, 75-97.

37 C. G. Claessens, M. V. Martínez-Díaz and T. Torres, Supramolecular Chemistry, John Wiley \& Sons, Ltd, Chichester, UK, 2012.

38 O. A. Melville, T. M. Grant, B. Mirka, N. T. Boileau, J. Park and B. H. Lessard, Adv. Electron. Mater., 2019, 5, 1900087.

39 J. Mack and N. Kobayashi, Chem. Rev., 2011, 111, 281-321.

40 N. Kobayashi, S. Nakajima, H. Ogata and T. Fukuda, Chem. - Eur. J., 2004, 10, 6294-6312.

41 N. Kobayashi, T. Furuyama and K. Satoh, J. Am. Chem. Soc., 2011, 133, 19642-19645.

42 T. Furuyama, K. Satoh, T. Kushiya and N. Kobayashi, J. Am. Chem. Soc., 2014, 136, 765-776.

43 Q. Li, Q. Tang, H. Li, W. Hu, X. Yang, Z. Shuai, Y. Liu and D. Zhu, Pure Appl. Chem., 2008, 80, 2231-2240.

44 O. A. Melville, B. H. Lessard and T. P. Bender, ACS Appl. Mater. Interfaces, 2015, 7, 13105-13118.

45 P. Sayer, M. Gouterman and C. R. Connell, Acc. Chem. Res., 1982, 15, 73-79.

46 M. S. Rodríguez-Morgade and P. A. Stuzhin, J. Porphyrins Phthalocyanines, 2004, 08, 1129-1165.

47 T. Furuyama and N. Kobayashi, Phys. Chem. Chem. Phys., 2017, 19, 15596-15612.

48 N. B. McKeown, Phthalocyanine materials: synthesis, structure, and function, Cambridge University Press, Cambridge, U.K., 1998.

49 A. B. Sorokin, Chem. Rev., 2013, 113, 8152-8191.

50 C. G. Claessens, D. González-Rodríguez, M. S. RodríguezMorgade, A. Medina and T. Torres, Chem. Rev., 2014, 114, 2192-2277.

51 D. Zdravkovski and M. C. Milletti, THEOCHEM, 2005, 717, 85-89.

52 N. Beaumont, J. S. Castrucci, P. Sullivan, G. E. Morse, A. S. Paton, Z. H. Lu, T. P. Bender and T. S. Jones, J. Phys. Chem. C, 2014, 118, 14813-14823.

53 B. Verreet, K. Cnops, D. Cheyns, P. Heremans, A. Stesmans, G. Zango, C. G. Claessens, T. Torres and B. P. Rand, $A d v$. Energy Mater., 2014, 4, 1-8.

54 K. L. Mutolo, E. I. Mayo, B. P. Rand, S. R. Forrest and M. E. Thompson, J. Am. Chem. Soc., 2006, 128, 8108-8109. 
55 G. E. Morse, J. L. Gantz, K. X. Steirer, N. R. Armstrong and T. P. Bender, ACS Appl. Mater. Interfaces, 2014, 6, 1515-1524.

56 C. E. Mauldin, C. Piliego, D. Poulsen, D. A. Unruh, C. Woo, B. Ma, J. L. Mynar and J. M. J. Fréchet, ACS Appl. Mater. Interfaces, 2010, 2, 2833-2838.

57 J. D. Virdo, A. J. Lough and T. P. Bender, Acta Crystallogr., Sect. C: Struct. Chem., 2016, 72, 297-307.

58 C. G. Claessens, D. González-Rodríguez and T. Torres, Chem. Rev., 2002, 102, 835-853.

59 C. G. Claessens, D. González-Rodríguez, M. S. RodríguezMorgade, A. Medina and T. Torres, Chem. Rev., 2014, 114, 2192-2277.

60 A. Meller and A. Ossko, Monatsh. Chem., 1972, 103, 150-155.

61 L. Giribabu, C. V. Kumar, A. Surendar, V. G. Reddy, M. Chandrasekharam and P. Y. Reddy, Synth. Commun., 2007, 37, 4141-4147.

62 C. G. Claessens, D. González-Rodríguez, B. del Rey, T. Torres, G. Mark, H.-P. Schuchmann, C. von Sonntag, J. G. MacDonald and R. S. Nohr, Eur. J. Org. Chem., 2003, 2547-2551.

63 P. A. Stuzhin, I. A. Skvortsov, Y. A. Zhabanov, N. V. Somov, O. V. Razgonyaev, I. A. Nikitin and O. I. Koifman, Dyes Pigm., 2019, 162, 888-897.

64 H. Gotfredsen, F. E. Storm, A. V. Muñoz, M. Santella, A. Kadziola, O. Hammerich, K. V. Mikkelsen and M. B. Nielsen, Chem. - Eur. J., 2017, 23, 16194-16198.

65 M. Hamdoush, S. S. Ivanova, G. L. Pakhomov and P. A. Stuzhin, Macroheterocycles, 2016, 9, 230-233.

66 M. Hamdoush, I. A. Skvortsov, M. S. Mikhailov, G. Pakhomov and P. A. Stuzhin, J. Fluorine Chem., 2017, 204, 31-36.

67 M. Hamdoush, K. Nikitin, I. Skvortsov, N. Somov, Y. Zhabanov and P. A. Stuzhin, Dyes Pigm., 2019, 170, 107584.

68 C. D. Zyskowski and V. O. Kennedy, J. Porphyrins Phthalocyanines, 2000, 4, 707-712.

69 S. Shimizu, S. Nakano, T. Hosoya and N. Kobayashi, Chem. Commun., 2011, 47, 316-318.

70 S. Shimizu, A. Miura, S. Khene, T. Nyokong and N. Kobayashi, J. Am. Chem. Soc., 2011, 133, 17322-17328.

71 B. A. Kamino and T. P. Bender, Dalton Trans., 2013, 42, 13145.

72 H. Shang, L. Zhao, D. Qi, C. Chen and J. Jiang, Chem. - Eur. J., 2014, 20, 16266-16272.

73 M. M. Nečedová, P. Magdolen, A. Fülöpová, M. Cigáň, P. Zahradník and J. Filo, Dyes Pigm., 2016, 130, 24-36.

74 Y. Wang, K. Uchihara, S. Mori, H. Furuta and S. Shimizu, Org. Lett., 2019, 21, 3103-3107.

75 L. Tejerina, M. V. Martínez-Díaz and T. Torres, Org. Lett., 2019, 21, 2908-2912.

76 N. Kobayashi, J. Chem. Soc., Chem. Commun., 1991, 1203.

77 T. Fukuda, J. R. Stork, R. J. Potucek, M. M. Olmstead, B. C. Noll, N. Kobayashi and W. S. Durfee, Angew. Chem., Int. Ed., 2002, 41, 2565-2568.

78 S. Nakano, Y. Kage, H. Furuta, N. Kobayashi and S. Shimizu, Chem. - Eur. J., 2016, 22, 7706-7710.
79 Y. Zhang, J. Oh, K. Wang, D. Shin, X. Zhan, Y. Zheng, D. Kim and J. Jiang, Chem. Commun., 2016, 52, 10517-10520.

80 M. Hanack and M. Geyer, J. Chem. Soc., Chem. Commun., 1994, 2253.

81 J. Rauschnabel and M. Hanack, Tetrahedron Lett., 1995, 36, 1629-1632.

82 M. Geyer, F. Plenzig, J. Rauschnabel, M. Hanack, B. Del Rey, A. Sastre and T. Torres, Synthesis, 1996, 1139-1151.

83 K. Goto, T. Kubo, K. Yamamoto, K. Nakasuji, K. Sato, D. Shiomi, T. Takui, M. Kubota, T. Kobayashi, K. Yakusi and J. Ouyang, J. Am. Chem. Soc., 1999, 121, 1619-1620.

84 M. V. Martínez-Díaz, B. del Rey, T. Torres, B. Agricole, C. Mingotaud, N. Cuvillier, G. Rojo and F. Agulló-López, J. Mater. Chem., 1999, 9, 1521-1526.

85 D. González-Rodríguez, T. Torres, E. L. G. Denardin, D. Samios, V. Stefani and D. S. Corrêa, J. Organomet. Chem., 2009, 694, 1617-1622.

86 D. González-Rodríguez, T. Torres, D. M. Guldi, J. Rivera, M. Á. Herranz and L. Echegoyen, J. Am. Chem. Soc., 2004, 126, 6301-6313.

87 P. V. Solntsev, K. L. Spurgin, J. R. Sabin, A. A. Heikal and V. N. Nemykin, Inorg. Chem., 2012, 51, 6537-6547.

88 N. Shibata, B. Das, E. Tokunaga, M. Shiro and N. Kobayashi, Chem. - Eur. J., 2010, 16, 7554-7562.

89 K. Adachi and H. Watarai, Anal. Chem., 2006, 78, 6840-6846.

90 G. E. Morse, J. S. Castrucci, M. G. Helander, Z. H. Lu and T. P. Bender, ACS Appl. Mater. Interfaces, 2011, 3, 3538-3544.

91 P. A. Barrett, D. A. Frye and R. P. Linstead, J. Chem. Soc., 1938, 1157.

92 D. Colaïtis, C. R. Hebd. Seances Acad. Sci., 1956, 242, 1026.

93 K. J. Wynne, Inorg. Chem., 1984, 23, 4658-4663.

94 J. Janczak and R. Kubiak, Inorg. Chim. Acta, 1999, 288, 174-180.

95 M. Hasegawa and N. Sato, Mol. Cryst. Liq. Cryst. Sci. Technol., Sect. A, 1997, 296, 409-426.

96 H. Yanik, D. Aydin, M. Durmuş and V. Ahsen, J. Photochem. Photobiol., A, 2009, 206, 18-26.

97 N. Masilela and T. Nyokong, J. Lumin., 2010, 130, 1787-1793.

98 M. Durmuş and T. Nyokong, Polyhedron, 2007, 26, 3323-3335.

99 Y. Chen, M. Hanack, Y. Araki and O. Ito, Chem. Soc. Rev., 2005, 34, 517-529.

100 N. Masilela and T. Nyokong, Dyes Pigm., 2010, 84, 242-248. 101 M. Hanack, T. Schneider, M. Barthel, J. S. Shirk, S. R. Flom and R. G. S. Pong, Coord. Chem. Rev., 2001, 219-221, 235-258.

102 Y. Chen, M. Hanack, W. J. Blau, D. Dini, Y. Liu, Y. Lin and J. Bai, J. Mater. Sci., 2006, 41, 2169.

103 M. J. Plater, A. Jeremiah and G. Bourhill, J. Chem. Soc., Perkin Trans. 1, 2002, 91-96.

104 J. E. Owen and M. E. Kenney, Inorg. Chem., 1962, 1, 331-333.

105 T. Schneider, H. Heckmann, M. Barthel and M. Hanack, Eur. J. Org. Chem., 2001, 3055-3065.

106 Y. Peng, F. Huang, J. Wen, B. Huang, X. Ma and Q. Wang, J. Coord. Chem., 2008, 61, 1503-1512. 
107 Y. Peng, P. Lin, J. Lin, G. Xu, H. Zhang and J. Shi, Mater. Lett., 2009, 63, 914-916.

108 D. Guay, J. P. Dodelet, R. Côté, C. H. Langford and D. Gravel, J. Electrochem. Soc., 1989, 136, 2272-2280.

109 K. Yamasaki, O. Okada, K. Inami, K. Oka, M. Kotani and H. Yamada, J. Phys. Chem. B, 1997, 101, 13-19.

110 J. P. Linsky, T. R. Paul, R. S. Nohr and M. E. Kenney, Inorg. Chem., 1980, 19, 3131-3135.

111 B. H. Lessard, M. Al-Amar, T. M. Grant, R. White, Z. H. Lu and T. P. Bender, J. Mater. Chem. A, 2015, 3, 5047-5053.

112 T. M. Grant, V. McIntyre, J. Vestfrid, H. Raboui, R. T. White, Z. H. Lu, B. H. Lessard and T. P. Bender, ACS Omega, 2019, 4, 5317-5326.

113 G. A. Kraus and S. J. Vander Louw, Synlett, 1996, 726.

114 H. Raboui, M. Al-Amar, A. I. Abdelrahman and T. P. Bender, RSC Adv., 2015, 5, 45731-45739.

115 Y. Chen, M. Hanack, S. O'Flaherty, G. Bernd, A. Zeug, B. Roeder and W. J. Blau, Macromolecules, 2003, 36, 3786-3788.

116 Y. Sakai, M. Ueda, A. Yahagi and N. Tanno, Polymer, 2002, 43, 3497-3503.

117 Y.-X. Li, J. Zhu, Y. Chen, J. Zhang, J. Wang, B. Zhang, Y. He and W. J. Blau, Nanotechnology, 2011, 22, 205704.

118 Y. Kojima, Y. T. Osano and T. Ohashi, Bull. Chem. Soc. Jpn., 2000, 73, 2469-2475.

119 P. A. Barrett, C. E. Dent and R. P. Linstead, J. Chem. Soc., 1936, 1719-1736.

120 R. D. Joyner, J. Cekada, R. G. Linck and M. E. Kenney, J. Inorg. Nucl. Chem., 1960, 15, 387-388.

121 R. D. Joyner and M. E. Kenney, Inorg. Chem., 1962, 1, 236-238.

122 M. K. Lowery, A. J. Starshak, J. N. Esposito, P. C. Krueger and M. E. Kenney, Inorg. Chem., 1965, 4, 128.

123 C. W. Dirk, T. Inabe, K. F. Schoch and T. J. Marks, J. Am. Chem. Soc., 1983, 105, 1539-1550.

124 S. O. Noboru Sasa, Kenji Okada and Kazuo Nakamura, J. Mol. Struct., 1998, 446, 163-178.

125 N. J. Yutronkie, T. M. Grant, O. A. Melville, B. H. Lessard and J. L. Brusso, Materials, 2019, 12, 1334.

126 R. D. Joyner and M. E. Kenney, J. Am. Chem. Soc., 1960, 82, 5790-5791.

127 J. Janczak and R. Kubiak, Acta Crystallogr., Sect. C: Cryst. Struct. Commun., 2003, 59, 237-240.

128 A. Slodeka, G. Schnurpfeilb and D. Wöhrle, J. Porphyrins Phthalocyanines, 2017, 21, 811-823.

129 R. L. Stover, C. L. Thrall and R. D. Joyner, Inorg. Chem., 1971, 10, 2335-2337.

130 J. B. Davison and K. J. Wynne, Macromolecules, 1978, 11, 186-191.

131 B. H. Lessard, J. D. Dang, T. M. Grant, D. Gao, D. S. Seferos and T. P. Bender, ACS Appl. Mater. Interfaces, 2014, 6, 15040-15051.

132 C. A. Barker, K. S. Findlay, S. Bettington, A. S. Batsanov, I. F. Perepichka, M. R. Bryce and A. Beeby, Tetrahedron, 2006, 62, 9433-9439.

133 J. N. Esposito, L. E. Sutton and M. E. Kenney, Inorg. Chem., 1967, 6, 1116-1120.
134 Y. Bandera, M. K. Burdette, J. A. Shetzline, R. Jenkins, S. E. Creager and S. H. Foulger, Dyes Pigm., 2016, 125, 72-79.

135 Z. Biyiklioğlu, Dyes Pigm., 2013, 99, 59-66.

136 E. T. Saka, H. Yalazan, Z. Blyıklıglu, H. Kantekin and K. Tekintas, J. Mol. Struct., 2020, 1199, 126994.

137 B. Xiao, M. Zhu, X. Li, P. Yang, L. Qiu and C. Lu, Int. J. Hydrogen Energy, 2016, 41, 11537-11546.

138 D. Ma, X. Chen, Y. Wang, Q. Guo, Q. Ye, R. Guo, S. Xiao, Q. Ye, Y. Huang and Y. Peng, J. Lumin., 2019, 207, 597-601.

139 K. N. Kim, C. S. Choi and K. Y. Kay, Tetrahedron Lett., 2005, 46, 6791-6795.

140 Z. Biyiklioglu and H. Alp, Dyes Pigm., 2016, 132, 213-222.

141 M. Hanack, K. Mitulla, G. Pawlowshi and L. R. Subramanian, J. Organomet. Chem., 1981, 204, 315-325.

142 W. J. Kroenke and M. E. Kenney, Inorg. Chem., 1964, 3, 251-254.

143 R. Seoudi, G. S. El-Bahy and Z. A. El Sayed, J. Mol. Struct., 2005, 753, 119-126.

144 I. Eneva, M. Aliosman, I. Angelov, K. Popov and V. Mantareva, Bulg. Chem. Commun., 2017, 49, 246-252.

145 W. E. Ford, M. A. J. Rodgers, L. A. Schechtman, J. R. Sounik, B. D. Rihter and M. Kenney, Inorg. Chem., 1992, 31, 3371-3377.

146 J. Kašpar, I. Emmer and R. A. Collins, Int. J. Electron., 1994, 76, 793-796.

147 M. Yamana and N. Kashiwazaki, Sens. Actuators, B, 1997, 40, 237-241.

148 N. M. Kuprikova, D. D. Klyamer, A. S. Sukhikh, P. O. Krasnov, I. Mrsic and T. V. Basova, Dyes Pigm., 2020, 173, 107939.

149 S. Maree, D. Phillips and T. Nyokong, J. Porphyrins Phthalocyanines, 2002, 06, 17-25.

150 R. Rafaeloff, F. J. Kohl, P. C. Krueger and M. E. Kenney, J. Inorg. Nucl. Chem., 1966, 28, 899-902.

151 T. M. Grant, N. A. Rice, L. Muccioli, F. Castet and B. H. Lessard, ACS Appl. Electron. Mater., 2019, 1, 494-504.

152 S. R. Forrest, Nature, 2004, 428, 911-918.

153 C. R. Newman, C. D. Frisbie, D. A. Da Silva Filho, J. L. Brédas, P. C. Ewbank and K. R. Mann, Chem. Mater., 2004, 16, 4436-4451.

154 J. Veres, S. Ogier, G. Lloyd and D. De Leeuw, Chem. Mater., 2004, 16, 4543-4555.

155 C. D. Dimitrakopoulos and P. R. L. Malenfant, Adv. Mater., 2002, 14, 99-117.

156 J. Zaumseil and H. Sirringhaus, Chem. Rev., 2007, 107, 1296-1323.

157 J. Roncali, P. Leriche and A. Cravino, Adv. Mater., 2007, 19, 2045-2060.

158 C. D. Dimitrakopoulos and D. J. Mascaro, IBM J. Res. Dev., 2001, 45(1), 11-27.

159 Y. Zhang, X. Cai, Y. Bian and J. Jiang, Functional Phthalocyanine Molecular Materials, 2010, pp. 275-321.

160 T. Yasuda and T. Tsutsui, Jpn. J. Appl. Phys., 2006, 45, L595-L597.

161 S. Md. Obaidulla, D. K. Goswami and P. K. Giri, Appl. Phys. Lett., 2014, 104, 213302. 
162 D. Song, H. Wang, F. Zhu, J. Yang, H. Tian, Y. Geng and D. Yan, Adv. Mater., 2008, 20, 2142-2144.

163 L. Li, W. Hu, H. Fuchs and L. Chi, Adv. Energy Mater., 2011, 1, 188-193.

164 A. Cricenti, L. Riele, B. Buick, E. Speiser, B.-O. Fimland, P. Vogt and W. Richter, Epioptics-11, 2012, 1-15.

165 D. Yan, D. Song, F. Zhu and B. Yu, US 7871855 B2, 2011.

166 D. Song, F. Zhu, B. Yu, L. Huang, Y. Geng and D. Yan, Appl. Phys. Lett., 2008, 92, 90-93.

167 M. M. Ling, Z. Bao and P. Erk, Appl. Phys. Lett., 2006, 89, 4-7.

168 Z. Bao, A. J. Lovinger and A. Dodabalapur, Appl. Phys. Lett., 1996, 69, 3066-3068.

169 T. Takahashi, T. Takenobu, J. Takeya and Y. Iwasa, Appl. Phys. Lett., 2006, 88, 1-3.

170 Y. Peng, W. Lv, B. Yao, J. Xie, T. Yang, G. Fan, D. Chen, P. Gao, M. Zhou and Y. Wang, IEEE Trans. Electron Devices, 2013, 60, 1208-1212.

171 T. Yasuda and T. Tsutsui, Mol. Cryst. Liq. Cryst., 2006, 462, 3-9.

172 R. Schmechel, M. Ahles and H. von Seggern, J. Appl. Phys., 2005, 98, 084511.

173 X. K. Chen, L. Y. Zou, J. F. Guo and A. M. Ren, J. Mater. Chem., 2012, 22, 6471-6484.

174 A. Facchetti, Chem. Mater., 2011, 23, 733-758.

175 J. C. Sancho-García, A. J. Pérez-Jiménez, Y. Olivier and J. Cornil, Phys. Chem. Chem. Phys., 2010, 12, 9381-9388.

176 Y. Sakamoto, T. Suzuki, M. Kobayashi, Y. Gao, Y. Fukai, Y. Inoue, F. Sato and S. Tokito, J. Am. Chem. Soc., 2004, 126, 8138-8140.

177 H. Geng, Y. Niu, Q. Peng, Z. Shuai, V. Coropceanu and J.-L. Brédas, J. Chem. Phys., 2011, 135, 104703.

178 Z. Bao, A. J. Lovinger and J. Brown, J. Am. Chem. Soc., 1998, 120, 207-208.

179 Z. Wang, C. Kim, A. Facchetti and T. J. Marks, J. Am. Chem. Soc., 2007, 129, 13362-13363.

180 M. Y. Kuo, H. Y. Chen and I. Chao, Chem. - Eur. J., 2007, 13, 4750-4758.

181 B. A. Jones, M. J. Ahrens, M. H. Yoon, A. Facchetti, T. J. Marks and M. R. Wasielewski, Angew. Chem., Int. Ed., 2004, 43, 6363-6366.
182 G. R. Hutchison, M. A. Ratner and T. J. Marks, J. Am. Chem. Soc., 2005, 127, 2339-2350.

183 X. K. Chen, J. F. Guo, L. Y. Zou, A. M. Ren and J. X. Fan, J. Phys. Chem. C, 2011, 115, 21416-21428.

184 W. Gu, Y. Hu, Z. Zhu, N. Liu, J. Zhang and J. Wang, SolidState Electron., 2013, 89, 101-104.

185 H. Wang, F. Zhu, J. Yang, Y. Geng and D. Yan, Adv. Mater., 2007, 19, 2168-2171.

186 L. Li, Q. Tang, H. Li, X. Yang, W. Hu, Y. Song, Z. Shuai, W. Xu, Y. Liu and D. Zhu, Adv. Mater., 2007, 19, 2613-2617.

187 F. Pan, H. Tian, X. Qian, L. Huang, Y. Geng and D. Yan, Org. Electron., 2011, 12, 1358-1363.

188 S. M. Yoon, H. J. Song, I. C. Hwang, K. S. Kim and H. C. Choi, Chem. Commun., 2010, 46, 231-233.

189 Y. Takabayashi and K. Prassides, 50 Years of Structure and Bonding - The Anniversary Volume, 2016, Google Livros.

190 G. Chaidogiannos, F. Petraki, N. Glezos, S. Kennou and S. Nešpůrek, Mater. Sci. Eng., B, 2008, 152, 105-108.

191 G. Chaidogiannos, F. Petraki, N. Glezos, S. Kennou and S. Nešpůrek, Appl. Phys. A: Mater. Sci. Process., 2009, 96, 763-767.

192 M. E. Sánchez-Vergara, L. Hamui and S. González Habib, Materials, 2019, 12, 1712.

193 J. S. Castrucci, M. G. Helander, G. E. Morse, Z. H. Lu, C. M. Yip and T. P. Bender, Cryst. Growth Des., 2012, 12, 1095-1100.

194 T. M. Grant, K. L. C. Kaller, T. J. Coathup, N. A. Rice, K. Hinzer and B. H. Lessard, Org. Electron., 2020, 87, 105976.

195 M. T. Dang, T. M. Grant, H. Yan, D. S. Seferos, B. H. Lessard and T. P. Bender, J. Mater. Chem. A, 2017, 5, 12168-12182.

196 Z. Bao, A. J. Lovinger and A. Dodabalapur, Adv. Mater., 1997, 9, 42-44.

197 S. Song, F. Ma, S. Wang, X. Li, X. Yin and F. Liu, Dig. J. Nanomater. Biostruct., 2017, 12, 119-126.

198 Y. Peng, P. Gao, W. Lv, B. Yao, G. Fan, D. Chen, J. Xie, M. Zhou, Y. Li and Y. Wang, IEEE Photonics Technol. Lett., 2013, 25, 2149-2152.

199 B. Mukherjee and M. Mukherjee, Org. Electron., 2009, 10, 1282-1287. 